\title{
əThe Influence of Antecedent Atmospheric River Conditions on Extratropical Cyclogenesis
}

\author{
ZHENHAI ZHANG ${ }^{\mathrm{a}}$ AND F. MARTIN RALPH ${ }^{\mathrm{a}}$ \\ ${ }^{a}$ Center for Western Weather and Water Extremes, Scripps Institution of Oceanography, University of California, San Diego, \\ San Diego, California
}

(Manuscript received 1 July 2020, in final form 31 January 2021)

\begin{abstract}
Some extratropical cyclones (ETC) begin their development in close proximity to a preexisting atmospheric river (AR). This study investigates the differences in the cyclogenesis stage between these cyclogenesis events and those that begin without an AR nearby. Well-established ETC and AR detection methods are applied to reanalysis over the North Pacific during the 1979-2009 cool seasons (November-March). Of the 3137 cyclogenesis cases detected, 35\% are associated with a nearby AR at the time of initial cyclogenesis. Of all 448 cyclones that deepened explosively in the $24 \mathrm{~h}$ after their initiation, $60 \%$ began with a preexisting AR nearby. The roles of both dry and diabatic processes that contribute to cyclogenesis are examined, specifically, low-level baroclinicity, upper-level forcing, water vapor inflow, and latent heating. ETCs that develop associated with a preexisting AR receive nearly $80 \%$ more water vapor inflow on average, enhancing latent heating and intensifying cyclone deepening in the genesis stage. In contrast, neither low-level baroclinicity nor upperlevel potential vorticity exhibit statistically significant differences between cyclogenesis events with and without an AR. Cyclogenesis events associated with an exceptionally strong AR at the ETC initial time deepen even more rapidly in the genesis stage, indicating that the intensity of an antecedent AR can modulate cyclogenesis. About half of the cyclogenesis cases off the U.S. West Coast are associated with ARs at their initial time. These results imply that errors in initial conditions related to ARs can contribute to errors in both AR and ETC predictions, as well as their concomitant impacts.
\end{abstract}

KEYWORDS: Atmospheric river; Extratropical cyclones; Cyclogenesis/cyclolysis; Diabatic heating; Water vapor

\section{Introduction}

This paper builds on the long history of research in extratropical cyclones (ETC), and the more recent understanding of atmospheric rivers (ARs). ARs are recognized as the primary region of strong horizontal water vapor transport often created by ETCs (Ralph et al. 2020a). However, it is clear that extratropical cyclogenesis (ETC-genesis) can occur in an environment with a preexisting, or "antecedent" AR (Sodemann and Stohl 2013; Zhang et al. 2019). This study uses modern ETC and AR tracking algorithms, applied to decades of reanalysis over the North Pacific Ocean, to quantify the occurrence of the ETC-genesis with an antecedent AR. It also explores the hypothesis that ETC deepening in the genesis stage can be intensified in such cases due to enhanced latent heating fueled by larger-than-normal inflow of water vapor by an antecedent AR into the developing ETC.

An ETC is a major low pressure system at the synoptic scale (horizontal length $\sim 1000 \mathrm{~km}$ ) and is the primary cool-season storm type in the midlatitudes. ETCs play an important role in both regional climate and daily weather, producing heavy precipitation and strong surface wind (e.g., Novak et al. 2008; Knox et al. 2011). Since the Norwegian conceptual model introduced by Bjerknes (1919), ETCs have been extensively studied for more than a century (Schultz et al. 2019; Dacre 2020). Generally, an ETC grows from the coupling and mutual

¿ Denotes content that is immediately available upon publication as open access.

Corresponding author: Zhenhai Zhang, zhz422@ucsd.edu amplification of low-level baroclinicity and upper-level forcing [upper-level potential vorticity (PV) and jet], with contributions from lower-tropospheric diabatic processes (Hoskins et al. 1985). While the importance of low-level baroclinicity and upper-level forcing has been widely recognized, the contribution of lower-tropospheric diabatic processes to ETC-genesis is still an active research topic (e.g., Zhang et al. 2019; Dacre 2020). Many case studies found that latent heat release can intensify ETC development (Danard 1964; Chang et al. 1984; Kuo et al. 1991; Lackmann 2002; Ahmadi-Givi et al. 2004; Hirata et al. 2016; Zhang et al. 2019). Some theoretical studies (Emanuel et al. 1987; Whitaker and Davis 1994) also came to conclusions consistent with those case studies, showing that latent heating could induce low-level potential vorticity (PV) and increase the growth rate of baroclinic instability.

In the early 1990s, the concept of an "atmospheric river" was introduced, as is described in a brief review of emergence of the concept (Ralph et al. 2020a). Recently the Glossary of Meteorology introduced a formal definition, including “ . . a a long, narrow, and transient corridor of strong horizontal water vapor transport that is typically associated with a lowlevel jet stream ahead of the cold front of an extratropical cyclone" (Ralph et al. 2018). Due to the nature of its definition, ARs are directly linked to water vapor transport. They play a significant role in transporting water vapor from the subtropics and tropics to the middle and high latitudes in the lower troposphere (Zhu and Newell 1998; Ralph et al. 2004; Bao et al. 2006; Stohl et al. 2008; Newman et al. 2012; Ralph et al. 2017). Zhu and Newell (1998) found that the majority of the meridional water vapor flux in midlatitudes was accomplished by ARs which covered only about $10 \%$ of the total hemispheric circumference, and Ralph et al. (2017) observed 
that an average AR transports as much water (as vapor) as 2.6 times the discharge of the world's largest terrestrial river, the Amazon. In addition, ARs are particularly important to precipitation, contributing to $30 \%-60 \%$ of local annual precipitation, which is vitally important to water supply (Guan et al. 2010; Dettinger 2011; Ralph et al. 2013; Lavers and Villarini 2015; Debbage et al. 2017; Gershunov et al. 2017). They also bring extreme precipitation and flooding (Ralph et al. 2006, 2013, 2016; Ralph and Dettinger 2012; Lavers and Villarini 2015), especially over western North America where the topography lifts the moist air, producing orographic precipitation.

Since the term AR was introduced in the 1990s, ARs have usually been linked to ETCs, because ARs are often found over the precold-frontal low-level jet region of an ETC (Ralph et al. 2004, 2005, 2006). Some previous studies (Dacre et al. 2015; Bao et al. 2006) suggested that ARs form in association with the warm conveyor belt (WCB, Browning 1990; Wernli and Davies 1997) in the ETC system with the local moisture convergence or the poleward moisture transport from the tropics/subtropics as the moisture source. However, recent studies suggested that AR and WCB are distinct from each other, although they are interrelated and often partially overlapped (Ralph et al. 2018; Sodemann et al. 2020). WCB is defined as strongly ascending warm and moist airstream in the warm sector of ETCs and is identified as a three-dimensional Lagrangian feature (Wernli and Davies 1997), while AR is defined as a long, narrow, and transient corridor of strong horizontal water vapor transport associated with the low-level jet of ETCs and is identified as a two-dimensional Eulerian feature (Ralph et al. 2018). Some studies considered an AR as a portion of the ETC system (Bao et al. 2006; Neiman et al. 2008; Dacre et al. 2015, 2019). For example, Dacre et al. (2015) suggested that the ARs were formed by the footprints left behind as ETCs traveled poleward from the subtropics for the most intense ETC cases. More studies showed cases where ARs were directly connected with the subtropical/tropical water vapor reservoir (Ralph et al. 2004, 2011; Neiman et al. 2011; Guan et al. 2012; Cordeira et al. 2013). However, it was shown by Cordeira et al. (2013) that most of the tropical water vapor had rained out prior to landfall on the U.S. West Coast, and that horizontal convergence of water vapor during the AR's evolution replenished the rainout that occurred along its trajectory.

While acknowledging the differences between ARs and ETCs, some studies clarified the distinct characteristics of ARs and ETCs (Sodemann and Stohl 2013; Hu et al. 2017). For example, Sodemann and Stohl (2013) found that ARs could span the lifetimes over multiple ETCs. Furthermore, Zhang et al. (2019) combined a modern ETC tracking algorithm (Hodges 1994, 1995; Colle et al. 2013) and an AR detection algorithm (Guan and Waliser 2015) to explore the spatial relationships of mature ARs and ETCs. By examining thousands of ETCs and ARs they found that over the eastern North Pacific and U.S. West Coast region nearly $20 \%$ of ARs occur without a nearby ETC and those ARs are usually close to a subtropical/tropical moisture source and include a nearby strong anticyclone. Thus, for a specific ETC, an AR may occur before the ETC-genesis since that AR may develop associated with a former ETC or exist independently from a nearby ETC. For example, Fig. 1 shows three ETC-genesis cases: case 1 (Figs. 1a-c) does not have a nearby AR, case 2 (Figs. 1d-f) has a preexisting AR over the southeast of ETC-genesis point and the ETC-genesis point is located close to the tail of the AR, and case 3 (Figs. 1g-i) has a relatively strong preexisting AR and the ETC-genesis point is located at the leading part of the AR. All of the three cases start from a low pressure area (Figs. 1a,d,g); after 6h they have the first closed SLP (ETCgenesis, Figs. 1b,e,h); and then the ETC centers deepen in the following $6 \mathrm{~h}$ (Figs. 1c,f,i). During the $12 \mathrm{~h}$, the minimum SLP deepened by about $4 \mathrm{hPa}$ for case $1,6 \mathrm{hPa}$ for case 2 , and $13 \mathrm{hPa}$ for case 3. While the influence of ETCs on ARs is widely recognized, the question being explored currently is whether a preexisting, or "antecedent" AR has any impacts on ETCgenesis that occurs nearby.

A few studies explored the interaction between ARs and ETCs. Zhu and Newell (1994) reported the association between explosive ETC-genesis (central pressure decreases at least $24 \mathrm{hPa}$ in $24 \mathrm{~h}$ ) and ARs based on a study of some selected cases. Eiras-Barca et al. (2018) found the concurrence of explosive ETCs and ARs; they hypothesized that it is the fingerprint of a mechanism that raises the odds of an explosive ETC-genesis occurrence. Zhang et al. (2019) investigated the relationship between ETC strength and AR intensity and position over the U.S. West Coast region. They demonstrated that while an ETC often intensifies the AR with stronger winddriven meridional water vapor transport, an AR can enhance the latent heat release and contribute to the ETC deepening. However, their study did not take the ETC life cycle into account and their ETC samples were collected within a domain of the U.S. West Coast, a decay region of the North Pacific storm track (Hoskins and Hodges 2002). As discussed above, an AR may occur before ETC-genesis and the antecedent AR could modulate the environment (such as water vapor) for the ETCgenesis. However, the potential influence of an antecedent AR on nearby ETC-genesis has not been fully examined. The objective of this study is to quantify the impacts of an antecedent AR on ETC deepening during the ETC-genesis stage over the North Pacific and explore the relevant dynamical and physical processes, especially the role of water vapor inflow from an antecedent AR into a developing ETC. This study addresses the following questions:

1) What fraction of extratropical cyclogenesis events develop near an antecedent atmospheric river?

2) What are the differences between extratropical cyclogenesis with and without an antecedent atmospheric river?

3) How will an antecedent atmospheric river affect extratropical cyclone deepening during the cyclogenesis stage?

4) Are there any significant differences in dry dynamical processes that affect the cyclone deepening in the cyclogenesis with and without an antecedent atmospheric river?

\section{Data and methods}

The Climate Forecast System Reanalysis (CFSR) data (Saha et al. 2010) from the National Centers for Environmental 

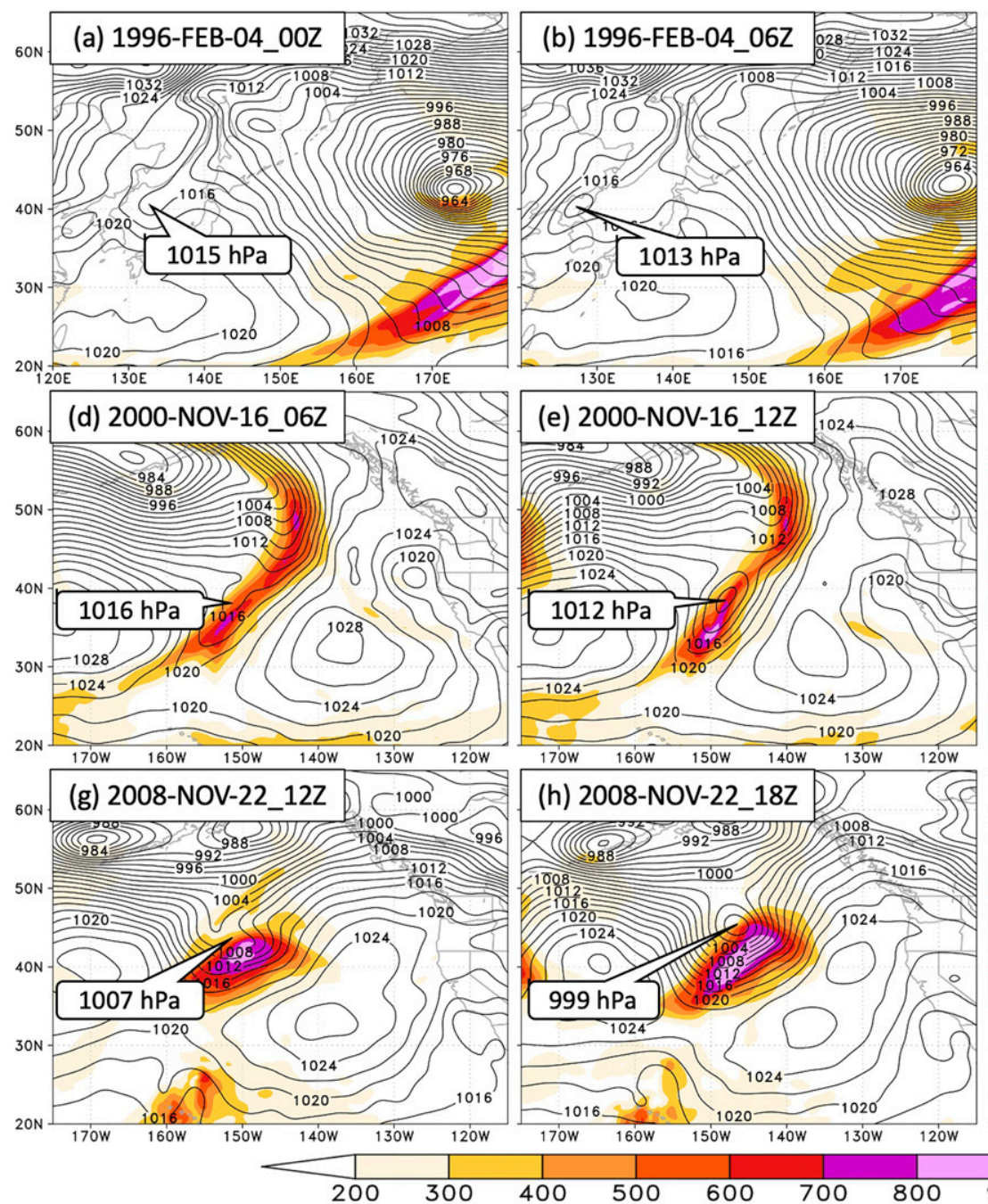
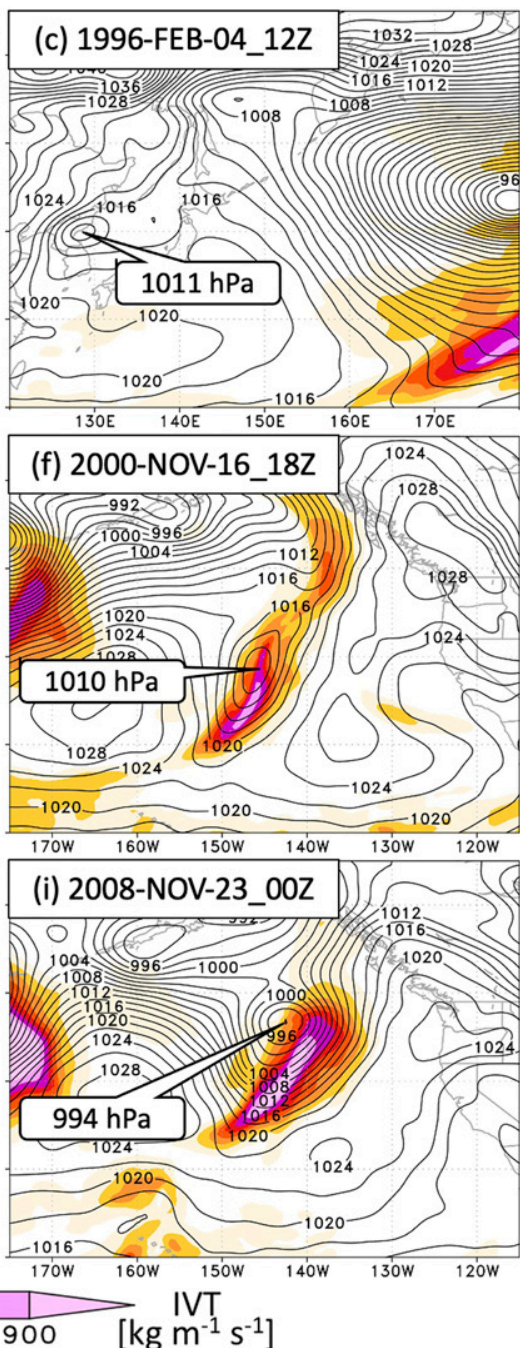

FIG. 1. (top) Sea level pressure (SLP; contours; hPa) and integrated water vapor transport (IVT; colors; $\mathrm{kg} \mathrm{m}^{-1} \mathrm{~s}^{-1}$ ) at (a) 0000 , (b) 0600 , and (c) 1200 UTC 4 Feb 1996 from CFSR. (middle) As in the top panels, but for (d) 0600, (e) 1200, and (f) 1800 UTC 16 Nov 2000. (bottom) As in the top panels, but for (g) 1200 UTC 22 Nov, (h) 1800 UTC 22 Nov, and (i) 0000 UTC 23 Nov 2008.

Prediction (NCEP) is used in this study. The resolution of CFSR is $\sim 38 \mathrm{~km}$ (T382) with 64 vertical levels. The data used in this study is obtained on $0.5^{\circ}$ longitude $\times 0.5^{\circ}$ latitude horizontal resolution, at 14 vertical levels $(1000,925,900,850,800$, $750,700,650,600,550,500,400,300$, and $200 \mathrm{hPa})$, and with a temporal resolution of 6-hourly. The CFSR data covers the time period from 1979 to 2010 . This study focuses on the boreal cool season (November-March) when both of ETCs and ARs are relatively active over the North Pacific. Hence, 31 cool seasons, from 1979-80 to 2009-10, are included in this study. The ETCs and ARs over the North Pacific domain (from $120^{\circ} \mathrm{E}$ to $115^{\circ} \mathrm{W}$ and from $25^{\circ}$ to $65^{\circ} \mathrm{N}$, Fig. 3) in those $31 \mathrm{cool}$ seasons were identified objectively and independently.

An objective cyclone tracking scheme (Hodges 1994, 1995) was employed to track the ETCs using 6-hourly sea level pressure (SLP). First, the SLP data were preprocessed using a spectral bandpass filter since SLP is strongly influenced by large spatial scales and strong background flow (Hoskins and Hodges 2002). Following Hoskins and Hodges (2002), the planetary scales with total wavenumber equal or less than 5 were removed. Meanwhile, following Zhang and Colle (2018), the SLP data were also truncated at small scales with total wavenumber larger than 70 (wavelength smaller than $\sim 400 \mathrm{~km}$ at $45^{\circ} \mathrm{N}$ ) to remove too small-scale noise. This is slightly larger than the wavenumber cutoff in some other studies (Hoskins and Hodges 2002; Hodges et al. 2011) because the CFSR data used in this study has relatively finer horizontal resolution and some small-scale ETCs can be identified with the 70-wavenumber cutoff. After the data preprocessing, the SLP minima in a time series were identified and linked to obtain the ETC tracks based on a cost function (Hodges 1995). At last, the minimum lifetime of $24 \mathrm{~h}$ and the minimum moving distance of $1000 \mathrm{~km}$ were used to exclude those low SLP centers that exist for a too short time or were too stationary. 
(a) Probability of AR Condition

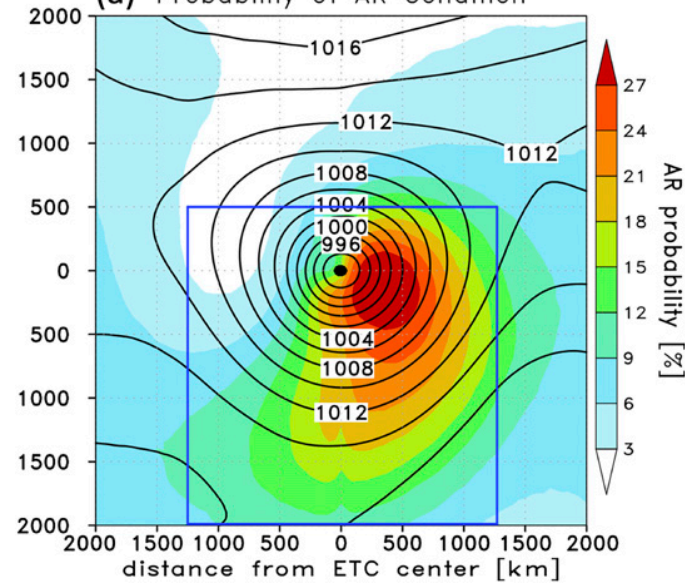

(b) AR IVT MAX Position

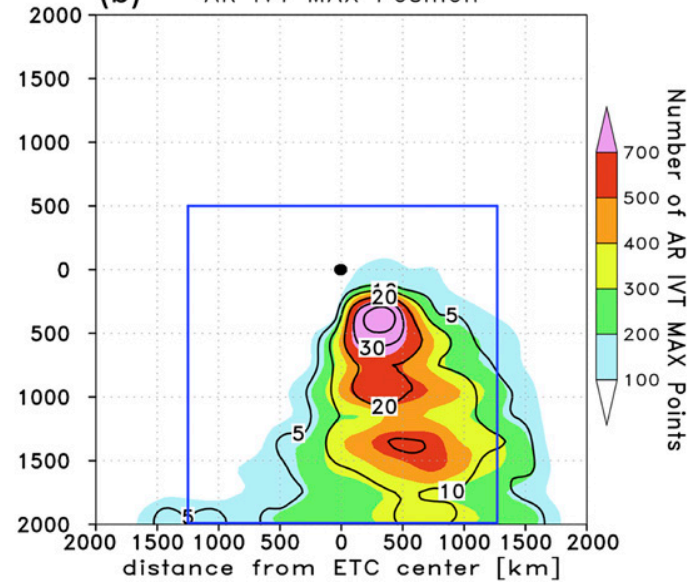

FIG. 2. (a): Probability (colors; \%) of atmospheric river (AR) condition and SLP (contours; hPa) around the composite extratropical cyclone (ETC) center (black dot). (b) The number of IVT maximum points for all ARs (colors) and exceptionally strong ARs (contours) in 31 (1979-2009) cool seasons in a unit area $\left(50000 \mathrm{~km}^{2}\right)$ around the composite ETC center (black dot). The blue box is used to define the association between ETC and AR.

The ETC tracking was conducted over the whole North Hemisphere and then only the ETCs with the genesis point in the North Pacific domain (from $120^{\circ} \mathrm{E}$ to $115^{\circ} \mathrm{W}$ and from $25^{\circ}$ to $65^{\circ} \mathrm{N}$, Fig. 3) were selected for this study. During the 31 cool seasons within the North Pacific domain, 3137 ETC tracks (events) were identified, including 62122 ETC centers. The ETC center was counted multiple times (every $6 \mathrm{~h}$ ) through the cyclone life cycle. On average, there are nearly 20 cyclone centers in each cyclone track, which means the averaged lifetime of those cyclones is nearly 5 days. This is consistent with the results in Hoskins and Hodges 2002. For each ETC track, the first identified ETC center was defined as the ETC-genesis point. Hence, 3137 ETC-genesis cases were used in this study.

The AR detection algorithm developed by Guan and Waliser (2015) was utilized to detect ARs using 6-hourly integrated water vapor transport (IVT). The IVT was calculated following Rutz et al. (2014) and was vertically integrated from 1000 to $200 \mathrm{hPa}$ (including 14 levels as described previously). First, at a specific grid cell the IVT value needs to be larger than the location- and season-dependent 85 th percentile of the IVT climatology at that grid cell, as well as a fixed lower limit of $100 \mathrm{~kg} \mathrm{~m}^{-1} \mathrm{~s}^{-1}$ (Guan and Waliser 2015). The grid cells with IVT larger than the threshold were identified as potential AR objects. Then the object was discarded if more than half of the grid cells had IVT deviating more than $45^{\circ}$ from the object's mean IVT direction, which ensured the coherence in IVT direction within an AR object. Finally, two geometry thresholds, length $>2000 \mathrm{~km}$ and length/width ratio $>2$, were applied to determine the final AR objects. Those detected ARs with a maximum IVT larger than $1250 \mathrm{~kg} \mathrm{~m}^{-1} \mathrm{~s}^{-1}$ were selected as exceptional AR cases following the AR intensity scale introduced by Ralph et al. (2019).

To reproduce the characteristics of a particular ETC category, a cyclone relative composite approach was applied following Zhang and Colle (2017). For each identified ETC center, a $4000 \mathrm{~km} \times 4000 \mathrm{~km}$ cyclone relative box around the ETC center was defined. Then the relevant fields (i.e., SLP, IVT) within this box were extracted as a sample of the corresponding ETC center. We used a large cyclone relative box $(4000 \mathrm{~km} \times 4000 \mathrm{~km})$ to ensure that it could capture the main part of the cyclones in different sizes. Meanwhile, the data were bilinearly interpolated from geographic latitudelongitude $\left(0.5^{\circ} \times 0.5^{\circ}\right)$ grid to $x-y(50 \mathrm{~km} \times 50 \mathrm{~km})$ grid to avoid the impact of latitude on the area of each grid cell. Since the ETC centers were flagged every $6 \mathrm{~h}$, those samples were also collected every $6 \mathrm{~h}$ for each ETC. Using the selected samples, the structure and amplitude of the relevant fields around the ETC center for a particular ETC category or a specific stage of the ETC life cycle can be reproduced objectively.

\section{Results}

\section{a. Association between ETC-genesis and AR}

To define the association between ETC-genesis and ARs, we first examined the spatial distribution of ARs related to the ETC center using all of the 62122 ETC centers, including ETC centers in different intensity and at different stages of cyclone life cycle, over the whole North Pacific domain in the 31 (19792009) cool seasons (November-March). Figure 2a shows the probability of AR occurrence and the averaged SLP around the composite ETC center. At a specific grid point around the cyclone center, the probability of AR occurrence is defined as the percentage of time when this grid point is in AR condition. The maximum probability of AR occurrence is about $28 \%$ located over the southeast of the ETC center, which means that if there is an ETC center, the averaged probability of AR condition at that maximum location is $\sim 28 \%$. The relatively high probability $(>12 \%)$ covers a large area from the northeast to the south side of the ETC center, extending nearly $2000 \mathrm{~km}$ 
far away from the ETC center. This distribution of AR probability is similar to the result from Zhang et al. (2019), which is based on 7224 ETC center samples within a domain of the U.S. West Coast, the decay region of the North Pacific storm track. However, Fig. 2 in this study provides a more robust result using much more ETC center samples (62 122) over the whole North Pacific storm track. Figure $2 b$ shows the distribution of the AR IVT maximum points around the composite ETC center. For both ARs and exceptional ARs (maximum IVT $>$ $1250 \mathrm{~kg} \mathrm{~m}^{-1} \mathrm{~s}^{-1}$ ), the IVT maxima are concentrated over the southeast of the ETC center around the low-level jet stream ahead of the cold front of the ETC. We also found that the AR IVT maximum points tend to be closer to the ETC center during the ETC genesis/developing stage and tend to be further away from the center during the ETC decay stage (not shown), which is very likely due to the change of ETC spatial structure in different stages of its life cycle.

Based on the results in Fig. 2 and following Zhang et al. (2019), the blue box in Fig. 2 is utilized to determine the association between ETC and AR. This box covers the main part of the high AR probability area as well as the IVT maximum points. Meanwhile, it is not too large so that the ARs too far away from the ETC center will be excluded since those ARs are more likely associated with some other dynamical systems. The size of this box could affect some results of this study. However, it does not have any significant impacts on the conclusions of this study if the box size is changed slightly (like $500 \mathrm{~km}$ in length or width) according to our sensitivity tests.

In this study, we focus on the ETC-genesis. If an AR exists within the blue box in Fig. 2 and its IVT maximum is also within the blue box at the ETC-genesis time point and/or one time step $(6 \mathrm{~h})$ before ETC-genesis, then this ETC-genesis case will be defined as ETC-genesis associated with an antecedent AR (AR-G); otherwise, it will be defined as ETC-genesis not associated with an antecedent AR (NO-AR-G). In addition to the NO-AR-G and the AR-G, the ETC-genesis associated with an antecedent exceptional AR (maximum IVT $>1250 \mathrm{~kg} \mathrm{~m}^{-1} \mathrm{~s}^{-1}$, namely AR Cat 5 following the AR intensity scale introduced by Ralph et al. 2019) is defined as AR5-G, which is a subset (extreme cases) of the AR-G category. The comparisons between the three types of ETCgenesis (the NO-AR-G, the AR-G, and the AR5-G) will be used to reveal the influence of the existence and the intensity of an antecedent AR on ETC-genesis.

\section{b. Difference between the three types of ETC-genesis}

The geophysical distribution of ETC-genesis density in the 31 cool seasons is calculated over the North Pacific domain. Figure 3a shows the ETC-genesis density of all cases. It has a maximum density over the western North Pacific (blue box) and a second-high density over the eastern North Pacific (red box). Overall, there are 101.2 ETC-genesis cases per cool season (total 3137 cases in 31 cool seasons) within the whole North Pacific domain, including 48.0 cases in the blue box and 26.9 cases in the red box per cool season (Table 1). These ETCgenesis cases are categorized into two types, the AR-G and the NO-AR-G using the approach described in section 3a. Of the 3137 ETC-genesis cases in the whole North Pacific domain,
$65.3 \%$ (2049 cases in 31 cool seasons) are NO-AR-G and $34.7 \%$ (1088 cases in 31 cool seasons) are AR-G cases (Table 1). However, there is large regional variability. In the western North Pacific domain (blue box) only $31.5 \%$ cases are AR-G, while in the eastern North Pacific domain (red box) $55.0 \%$ cases are AR-G (Fig. 3 and Table 1).

In the cool season, the climatological SLP pattern over the North Pacific is dominated by Aleutian low and North Pacific high (Fig. 3a). Over the western North Pacific region, the lowlevel baroclinicity is relatively strong due to the large temperature difference between the continent and the ocean in the cool season. The Eady growth rate at $850-500 \mathrm{hPa}$ (calculated following Colle et al. 2013), which assesses baroclinic instability (Hoskins and Valdes, 1990), has a maximum of 1.2 day $^{-1}$ over the western North Pacific (Fig. 3b). The major ETCgenesis region is just located at the beginning area of the Eady growth rate maximum, which is the entrance of the North Pacific storm track (Hoskins and Valdes 1990; Hoskins and Hodges 2002). Meanwhile, the diabatic processes may also play an important role in the ETC-genesis in the western North Pacific (Madonna et al. 2014). There is a second high ETCgenesis area over the eastern North Pacific region (red box in Fig. 3a), where the climatological water vapor content (measured as integrated water vapor, IWV) is relatively high (Fig. 3c). When an upper-level perturbation moves to this region, the diabatic processes may play an important role in ETC-genesis given sufficient water vapor supply, although the climatological baroclinicity over that region is relatively low.

The cyclone central SLP deepening in $24 \mathrm{~h}$ after ETCgenesis is examined to explore the difference of ETC development between the AR-G and the NO-AR-G events (Fig. 4). First, the cyclone deepening rate was normalized by latitude using $60^{\circ} \mathrm{N}$ as a reference following Sanders and Gyakum (1980) since the different latitudes had considerable impact on the cyclone intensification. Specifically, the new normalized deepening rate was obtained by dividing the original deepening rate by $\left(\sin \lambda / \sin 60^{\circ}\right)$, where $\lambda$ was the latitude of the cyclone center. Overall, the central SLP deepening of the AR-G ETCs is significantly quicker than the deepening of the NO-AR-G at the $95 \%$ confidence level. A Bootstrap resampling approach (Diaconis and Efron 1983) was utilized to conduct the statistical confidence level in this study. The frequency maximum is in the normalized deepening rate bin of $-12 \mathrm{hPa}$ for the AR-G ETCs and $-8 \mathrm{hPa}$ for the NO-AR-G (Fig. 4a). Compared to the NO-AR-G, the overall distribution of the AR-G ETC deepening shifts to the more rapid deepening side. Generally, the percentage of the AR-G ETCs increases with the 24-h SLP deepening, from $\sim 20 \%$ for nearly $0 \mathrm{hPa}$ change to $\sim 60 \%$ for over 30-hPa deepening (Fig. 4b). There are 448 identified explosive ETC-genesis cases (normalized deepening rate equal to or larger than $24 \mathrm{hPa}$ in the $24 \mathrm{~h}$ after ETC-genesis) over the North Pacific in the 31 cool seasons. In those explosive ETCgenesis cases, $60 \%$ are the AR-G cases and only $40 \%$ are the NO-AR-G. To sum up, the AR-G ETCs tend to deepen more quickly than the NO-AR-G in the $24 \mathrm{~h}$ after ETC-genesis.

In addition to the total deepening in the $24 \mathrm{~h}$ after ETCgenesis, the averaged time series of SLP and deepening rate through ETC-genesis stage (from $24 \mathrm{~h}$ before to $24 \mathrm{~h}$ after 


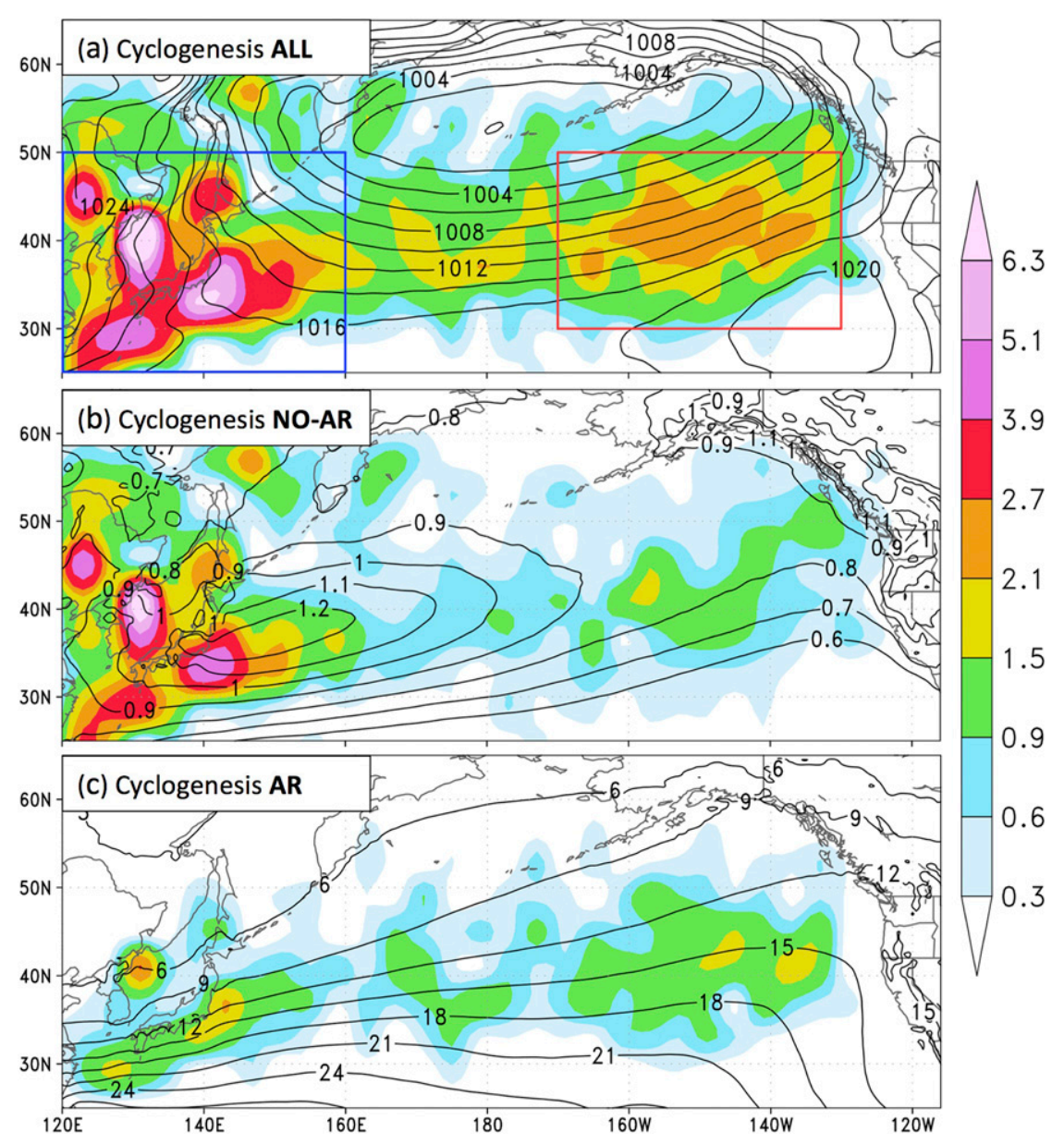

FIG. 3. (a) Cyclogenesis density (number per $50000 \mathrm{~km}^{2}$ per $10 \mathrm{cool}$ seasons) and average SLP (contours; hPa) in 31 (1979-2009) cool seasons over the North Pacific from CFSR. (b) As in (a), but for the cyclogenesis not associated with an antecedent AR and the average Eady growth rate (contours; day ${ }^{-1}$ ) at $850-500 \mathrm{hPa}$. (c) As in (a), but for the cyclogenesis associated with an antecedent AR and the average integrated water vapor (IWV; contours; mm).

ETC-genesis) are examined in Fig. 5. Since the ETC-genesis point is defined as the first ETC center of each detected ETC track, before ETC-genesis the SLP and deepening rate are actually obtained at a fix location, the ETC-genesis point. At and after ETC-genesis, SLP and deepening rate are the values at the ETC center. At $24 \mathrm{~h}$ before ETC-genesis $(-24 \mathrm{~h})$, the differences of SLP $(1.5 \mathrm{hPa})$ and deepening rate $(0.2 \mathrm{hPa}$ per $6 \mathrm{~h})$ between the AR-G and the NO-AR-G are small and not statistically significant due to the large spread of each category. Then the difference of deepening rate between the AR-G and the NO-AR-G increases with time. The deepening rate of the AR-G becomes significantly larger than the NO-AR-G from -6 to $+18 \mathrm{~h}$. As a result, the difference of SLP increases with time and at $+24 \mathrm{~h}$ the ETC central SLP of the AR-G (994 hPa) is about $8 \mathrm{hPa}$ deeper than the NO-AR-G $(1002 \mathrm{hPa})$. Meanwhile, the averaged deepening rate of the AR5-G is consistently larger than both of the NO-AR-G and the AR-G events from -24 to $+24 \mathrm{~h}$. These differences in the deepening rate indicate that the existence and the intensity of AR have great impacts on the ETC deepening in the ETC-genesis stage. The difference of ETC deepening rate between those three types of ETC may become smaller after $+24 \mathrm{~h}$. An AR may form (intensify) with the developing of the NO-AR-G (AR-G) ETCs, and

TABLE 1. Number of cases per cool season for all cyclogenesis, cyclogenesis not associated with an antecedent atmospheric river (NO-AR-G), and cyclogenesis associated with an antecedent atmospheric river (AR-G) in three domains, North Pacific (NP, the whole domain of Fig. 3a), western NP (blue box in Fig. 3a), and eastern NP (red box in Fig. 3a). Values in parentheses are the percentage of the all cyclogenesis count in each domain, respectively.

\begin{tabular}{lccc}
\hline \hline & North Pacific (NP) & Western NP & Eastern NP \\
\hline All cyclogenesis & $101.2(100 \%)$ & $48.0(100 \%)$ & $26.9(100 \%)$ \\
NO-AR-G & $66.1(65.3 \%)$ & $32.9(68.5 \%)$ & $12.1(45.0 \%)$ \\
AR-G & $35.1(34.7 \%)$ & $15.1(31.5 \%)$ & $14.8(55.0 \%)$ \\
\hline
\end{tabular}



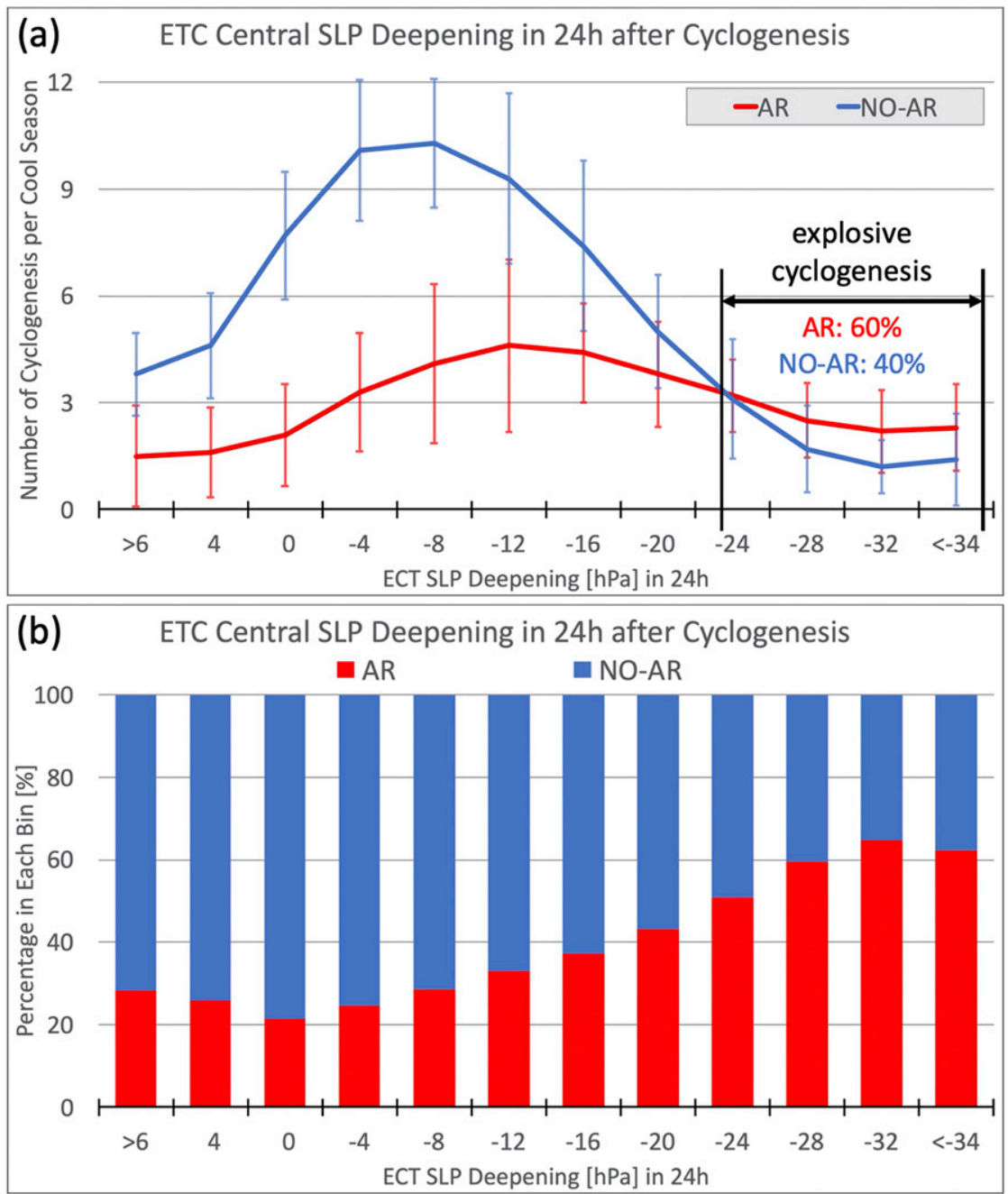

FIG. 4. (a) Distribution of normalized ETC central SLP deepening (hPa) in $24 \mathrm{~h}$ after cyclogenesis associated with an antecedent AR (red) and not associated with an antecedent AR (blue). The vertical bars denote the spread (one standard deviation) of cyclogenesis counts in each bin in 31 cool seasons. (b) Distribution of ETC central SLP deepening (hPa) in $24 \mathrm{~h}$ after cyclogenesis; the $y$ axis is the percentage (\%) of cyclogenesis associated with an AR (red) and not associated with an AR (blue) in each deepening rate bin.

then the differences in AR conditions and the ETC deepening rate between the three types of ETCs may become smaller in the following days.

\section{c. Relevant dynamical and physical processes}

\section{1) WATER VAPOR TRANSPORT}

To better understand the influence of an antecedent AR to ETC-genesis, the relevant dynamical and physical factors are compared between the AR-G and the NO-AR-G using the ETC composite fields based on the 1088 AR-G and 2049 NO-AR-G cases. The AR5-G (262 cases in 31 cool seasons) cases are also examined to investigate the impacts of AR intensity on ETC-genesis. Figures 6a-c show the composite mean SLP tendency and SLP in the $24 \mathrm{~h}$ before ETC-genesis, which is a critical time period to ETC-genesis. Most of the following composite figures are the $24 \mathrm{~h}$ average before ETC-genesis except Figs. 8 and 15, which are instantaneous fields. The NO-AR-G has a weak negative SLP tendency around $-1.0 \mathrm{hPa}$ per $6 \mathrm{~h}$ at the east side of ETC-genesis point, while the negative SLP tendency is around $-1.5 \mathrm{hPa}$ per $6 \mathrm{~h}$ for the AR-G and around $-2.0 \mathrm{hPa}$ per $6 \mathrm{~h}$ for the AR5-G (Figs. 6a-c).

Since the three types of ETC-genesis are defined based on the existence and intensity of an AR, the composite 24-h mean IVT before ETC-genesis exhibit a significant difference in Figs. $6 \mathrm{~d}-\mathrm{f}$. The maximum IVT is only $170 \mathrm{~kg} \mathrm{~m}^{-1} \mathrm{~s}^{-1}$ for the NO-AR-G cases, while it is about $310 \mathrm{~kg} \mathrm{~m}^{-1} \mathrm{~s}^{-1}$ (80\% stronger) for the AR-G and $410 \mathrm{~kg} \mathrm{~m}^{-1} \mathrm{~s}^{-1}$ (140\% stronger) for the AR5-G. The IVT spatial patterns of these three types are similar, exhibiting an IVT maximum located to the south of ETC-genesis point. 

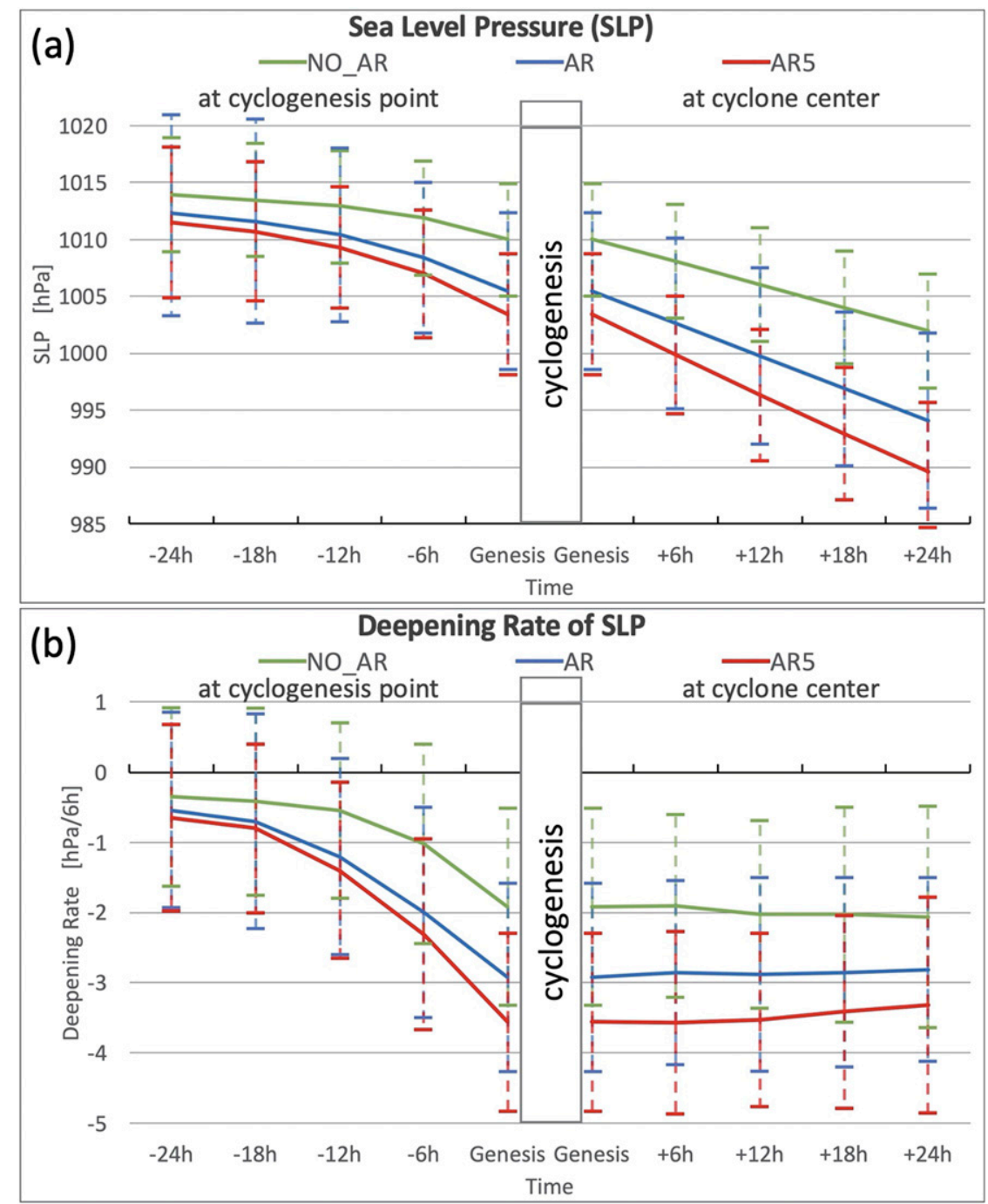

FIG. 5. (a) Time series of (left) SLP at the cyclogenesis point from $24 \mathrm{~h}$ before cyclogenesis $(-24 \mathrm{~h})$ to cyclogenesis and (right) SLP at ETC center from cyclogenesis to $24 \mathrm{~h}$ after cyclogenesis $(+24 \mathrm{~h})$ for the cases not associated with an antecedent AR (green), associated with an antecedent AR (blue), and associated with an antecedent exceptional AR (red). The vertical bars denote the spread (one standard deviation) of ETC central SLP at each time step. (b) As in (a), but for SLP deepening rate.

The large difference in IVT is mainly due to the different low-level wind and IWV. First, the SLP patterns are quite different for the NO-AR-G and the AR-G/AR5-G although both of them have a low pressure area around the ETC-genesis location (Figs. 6a-c). The NO-AR-G has a $1018 \mathrm{hPa}$ high pressure over the southwest side of the ETC-genesis point, while the AR-G/AR5-G also has a $1018 \mathrm{hPa}$ high pressure but over the southeast side of the ETC-genesis point. In addition, the minimum composite SLP at the ETC-genesis point is $1014 \mathrm{hPa}$ for the NO-AR-G, $1010 \mathrm{hPa}$ for the AR-G, and $1008 \mathrm{hPa}$ for the AR5-G. As a result, the NO-AR-G has a weak SLP gradient maximum at the south-southwest of the ETCgenesis point, while the AR-G has a strong and the AR5-G has an even stronger pressure gradient over the southeast side of the ETC-genesis point. These different composite SLP patterns for the three types of ETC-genesis are similar to the SLP patterns of the three individual ETC-genesis cases in Fig. 1, which provides more confidence to use the cyclone relative composite approach.

Due to the different SLP patterns, the low-level wind of the NO-AR-G, the AR-G, and the AR5-G exhibits large differences (Figs. 7a-c). The NO-AR-G has a weak low-level wind maximum $\left(\sim 7 \mathrm{~m} \mathrm{~s}^{-1}\right.$ at $\left.925 \mathrm{hPa}\right)$ over the south-southwest of the ETC-genesis point and the wind is relatively zonal. The zonal west wind and the weak IWV (Fig. 7d) produce an IVT maximum of only around $170 \mathrm{~kg} \mathrm{~m}^{-1} \mathrm{~s}^{-1}$ as shown in Fig. $6 \mathrm{~d}$. In contrast, the wind maximum at $925 \mathrm{hPa}$ for the AR-G is over $10 \mathrm{~m} \mathrm{~s}^{-1}$ along the strong SLP gradient area; and more 

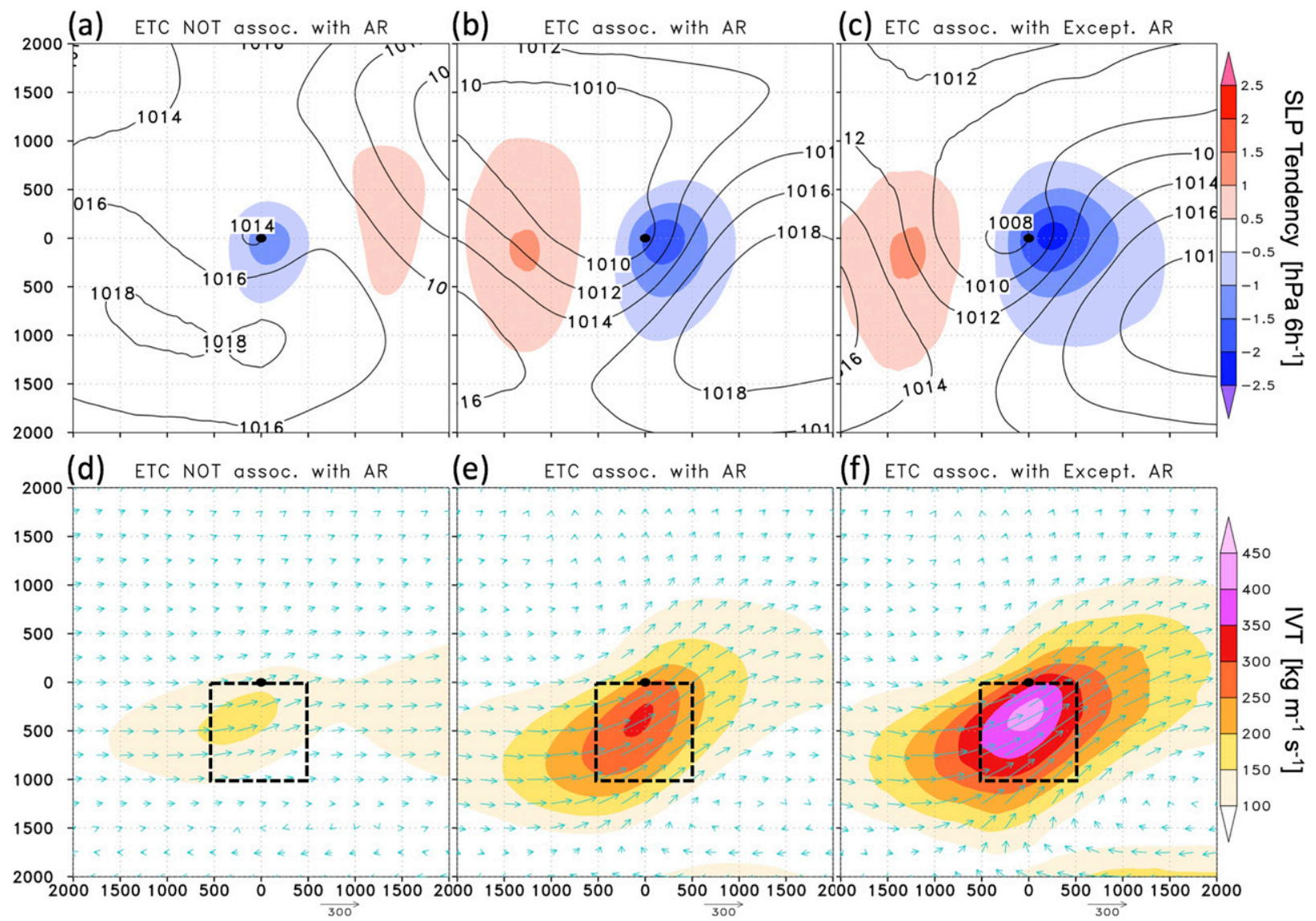

FIG. 6. Composite mean SLP tendency [colors; hPa $(6 \mathrm{~h})^{-1}$ ] and mean SLP (contours; $\mathrm{hPa}$ ) in the $24 \mathrm{~h}$ before cyclogenesis around the cyclogenesis point (black dot) (a) not associated with an antecedent AR, (b) associated with an antecedent AR, and (c) associated with an antecedent exceptional AR. (d)-(f) As in (a)-(c), but for IVT (colors and arrows; $\mathrm{kg} \mathrm{m}^{-1} \mathrm{~s}^{-1}$ ). The axes are the distance (km) from the cyclogenesis point. The small dashed black box in (d)-(f) is used to calculate mean IVT during cyclogenesis stage.

importantly, the wind direction is more meridional, from southwest to northeast (Fig. 7b). Given the strong southwest wind and the high IWV tongue over the south of the ETCgenesis point (Fig. 7e), the AR-G has a much stronger IVT maximum $\left(310 \mathrm{~kg} \mathrm{~m}^{-1} \mathrm{~s}^{-1}\right)$, which transports water vapor to the warm sector of the ETC (Fig. 6e). Compared to the AR-G, the AR5-G has similar patterns of low-level wind and IWV, but with stronger amplitudes (Figs. 7c,f), resulting in the strongest IVT maximum $\left(410 \mathrm{~kg} \mathrm{~m}^{-1} \mathrm{~s}^{-1}\right)$ as shown in Fig. 6f. The different low-level wind and IWV explain the large difference of mean IVT in the $24 \mathrm{~h}$ before ETC-genesis for these three types of ETC-genesis.

To further understand the difference of IVT between the AR-G and the NO-AR-G, the difference of low-level wind and IWV are examined at 18,12 , and $6 \mathrm{~h}$ before ETC-genesis, and the ETC-genesis time point (Fig. 8). Through the four time steps, the composite difference of low-level wind exhibits a convergence (dashed red contours in Fig. 8) over the south of the ETC-genesis point, and then a meridional wind from the south to the northeast at the warm sector of ETC. This pattern enhances the convergence of IWV and IWV accumulated within the convergence area, moving with the wind toward to the warm sector of the cyclone. From $18 \mathrm{~h}$ before ETC-genesis to the ETC-genesis time point, the IWV difference increases quickly and the difference maximum moves from the southwest side of ETC-genesis point to the warm front region (east side of ETC-genesis point). Therefore, an antecedent AR brings significantly more water vapor $(80 \%$ stronger IVT in Fig. 6) to the AR-G compared to the NO-AR-G. A similar comparison between the AR-G and the AR5-G shows that the AR5-G has even stronger IWV and low-level meridional wind than the AR-G (not shown), resulting the strongest IVT for the AR5-G (Fig. 6f).

The changes of IVT through the ETC-genesis stage (from $24 \mathrm{~h}$ before to $24 \mathrm{~h}$ after ETC-genesis) are shown as a time series of the mean IVT in Fig. 10a. The mean IVT was calculated within the dashed box in Figs. 6d-f, which covers the maximum IVT region for all of the three types of ETC-genesis. The time series in Fig. 10a shows that the AR-G has 55\%-76\% stronger IVT than the NO-AR-G though the ETC-genesis stage. Those differences are statistically significant at the $95 \%$ confidence level for all of the time steps except $-24 \mathrm{~h}(24 \mathrm{~h}$ before ETC-genesis). Compared to the AR-G, the AR5-G has $32 \%-43 \%$ stronger IVT during the ETC-genesis stage. It is not 

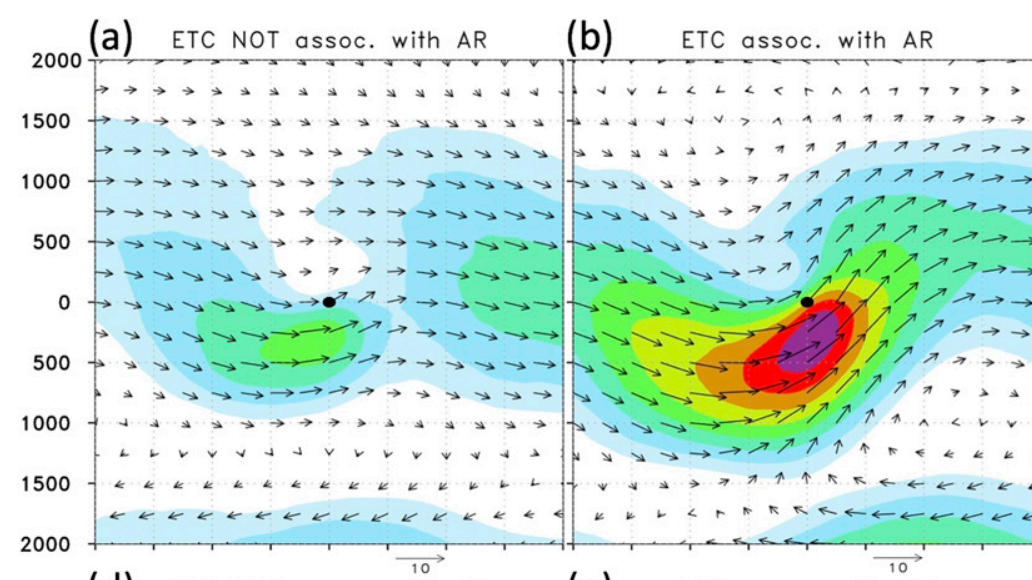

(c) ETC assoc. with Except. AR

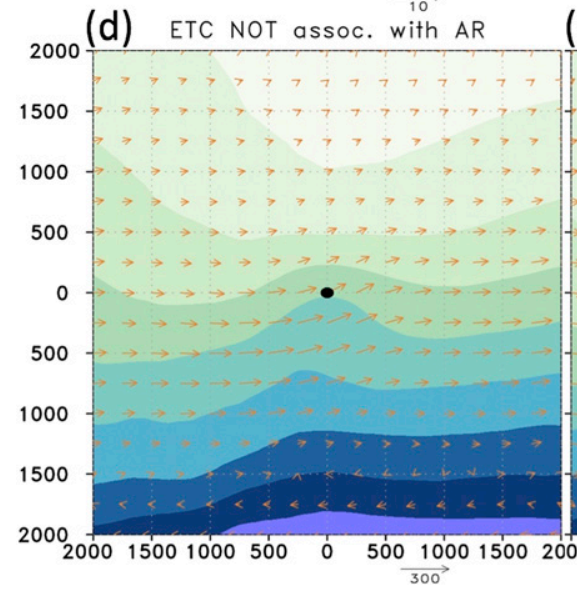

(e)

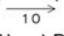

ETC assoc. with $A R$
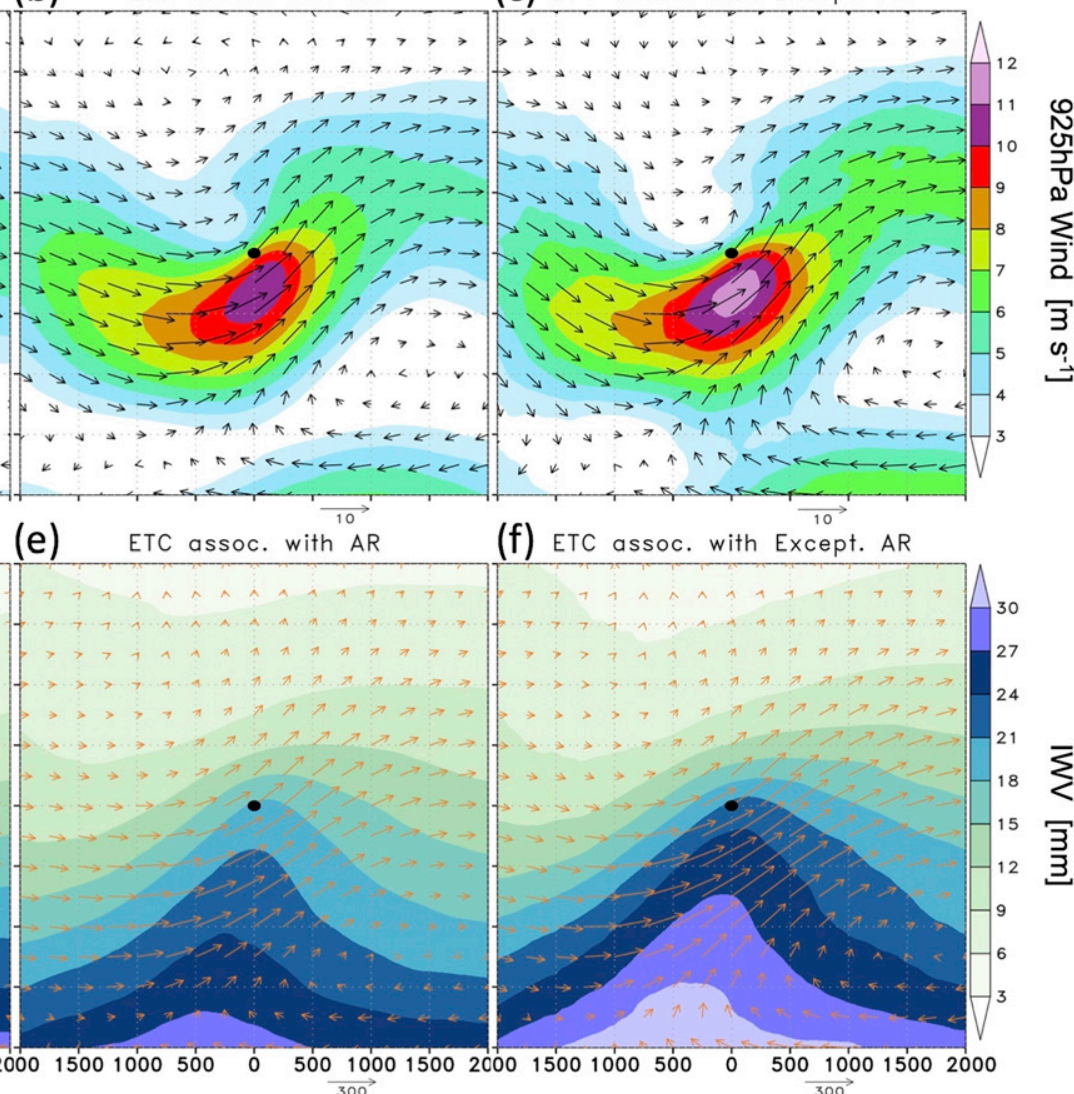

FIG. 7. As in Fig. 6, but for (a)-(c) 925-hPa wind (colors and arrows; $\mathrm{m} \mathrm{s}^{-1}$ ); (d)-(f) IWV (colors; mm) and IVT (arrows; $\mathrm{kg} \mathrm{m}^{-1} \mathrm{~s}^{-1}$ ).

surprising that the three types of ETC-genesis exhibit those differences in IVT since they are defined based on the existence and the intensity of an AR.

\section{2) DiAbATIC PROCESSES}

There is a large difference in the water vapor inflow to the diabatic processes for the three types of ETC-genesis. In addition, the AR-G has a stronger upward motion around the ETC-genesis point than the NO-AR-G (Figs. 9a,b). The composite pressure tendency (omega, $D p / D t$, where $p$ is pressure and $t$ is time) at $700 \mathrm{hPa}$ around the ETC-genesis point is about $-0.1 \mathrm{~Pa} \mathrm{~s}^{-1}$ for the NO-AR-G and about $-0.15 \mathrm{~Pa} \mathrm{~s}^{-1}$ for the AR-G. The strong upward motion in the warm sector of the AR-G ETC is very likely associated with ascending WCBs (Fig. 9b). Given the stronger water vapor transport and upward motion, the precipitation for the AR-G is significantly heavier than the NO-AR-G (not shown), and accordingly the latent heat release is stronger (Fig. 9b). The composite latent heating rate (calculated following Emanuel et al. 1987) around the AR-G has a maximum over $12 \mathrm{~K} \mathrm{day}^{-1}$ at $950-500 \mathrm{hPa}$, which is over $70 \%$ stronger than the NO-AR-G cases $\left(\sim 7 \mathrm{~K} \mathrm{day}^{-1}\right)$ as shown in Figs. 9a and 9b. The stronger latent heating can enhance the vertical motion and the generation of kinetic energy, which was investigated by many previous studies (Danard 1964; Chang et al. 1984). The latent heat release can also generate cyclonic diabatic potential vorticity $(\mathrm{PV})$ in the lower troposphere, which is an important factor to enhance ETC intensification in the genesis stage (Davis and Emanuel 1991; Stoelinga 1996; Lackmann 2002; Ahmadi-Givi et al. 2004; Willison et al. 2013). Following many previous studies (Marciano et al. 2015; Zhang and Colle 2018), the low-level $\mathrm{PV}$ at $900-750 \mathrm{hPa}$ is calculated and considered to be the diabatically produced low-level PV (Figs. 9d-f). The composite low-level PV for the AR-G has a maximum of over 1.0 PVU (1 PVU $=10^{-6} \mathrm{~K} \mathrm{~kg}^{-1} \mathrm{~m}^{2} \mathrm{~s}^{-1}$ ), which is about $80 \%$ stronger than the NO-AR-G (0.5-0.6 PVU). These results imply that an antecedent AR can provide sufficient water vapor to significantly strengthen the latent heat release and diabatic PV, and eventually enhance the ETC deepening in the genesis stage.

This is consistent with previous studies that investigate the contribution of the diabatic process to cyclone deepening from the WCB perspective (Wernli and Davies 1997; Madonna et al. 2014; Binder et al. 2016). The strong upward motion is located at the leading part of the composite AR IVT (Figs. 6e and 9e). It indicates that $\mathrm{AR}$ provides strong water vapor inflow to the ascending WCB, which enhances the diabatic process and produces low-level positive PV anomalies during the strong cloud and precipitation formation (Wernli and Davies 1997; Madonna et al. 2014; Binder et al. 2016). 


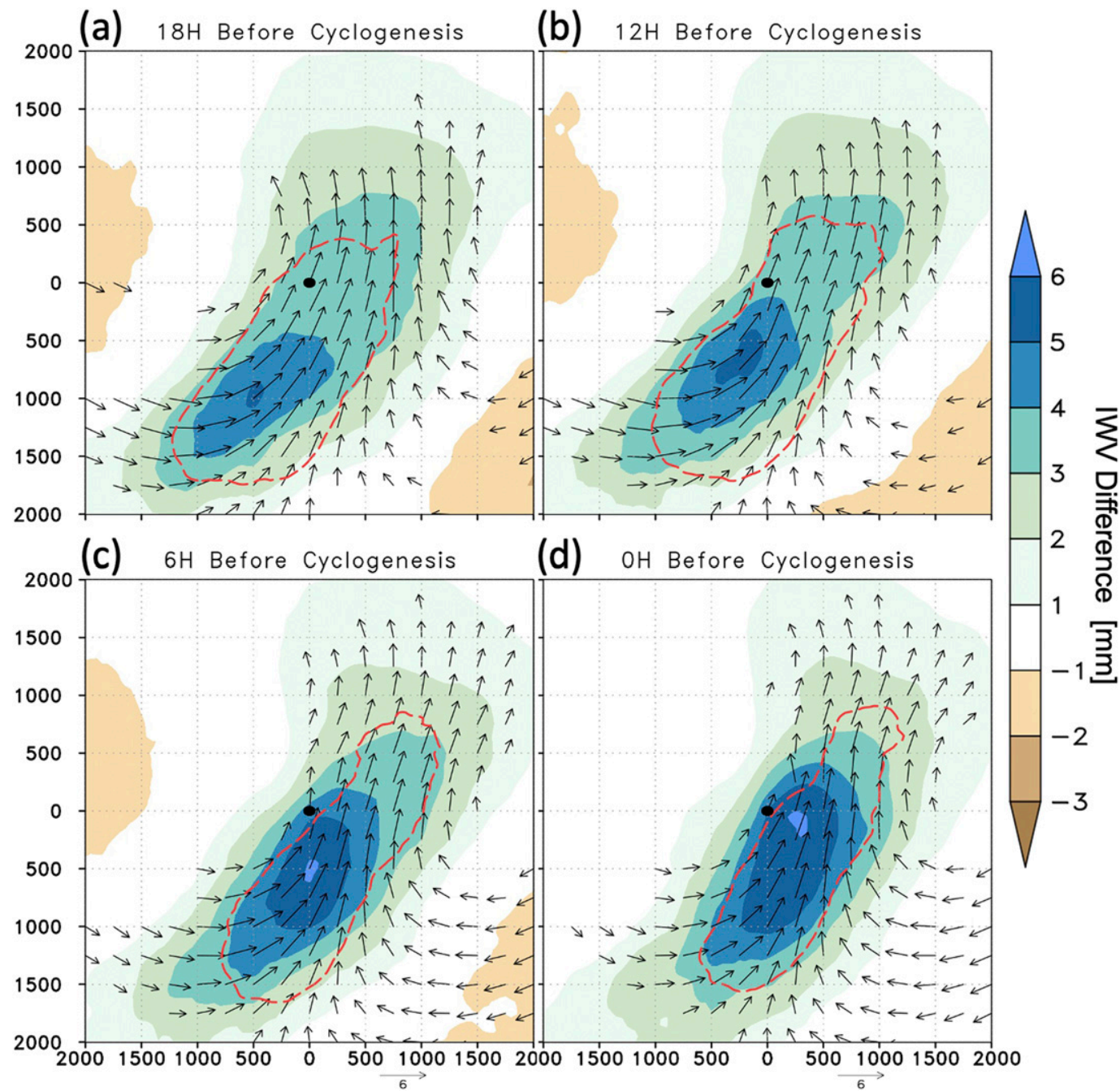

FIG. 8. Difference of composite IWV (colors; $\mathrm{mm}$ ) and 925-hPa wind (arrows; $\mathrm{m} \mathrm{s}^{-1}$ ) between the cyclogenesis associated with an antecedent AR (AR-G) and not associated with an antecedent AR (NO-AR-G) for (a) $18 \mathrm{~h}$, (b) $12 \mathrm{~h},(\mathrm{c}) 6 \mathrm{~h}$ before cyclogenesis, and (d) cyclogenesis time point (AR-G minus NO-AR-G). The dashed red line (divergence $=-1 \times 10^{-4} \mathrm{~s}^{-1}$ ) in each panel denotes the main convergence area of the wind difference. The black dot indicates the cyclogenesis point. Only the differences at statistical confidence level $95 \%$ are plotted.

Meanwhile, the AR5-G has even stronger diabatic processes. Compared to the NO-AR-G, the AR5-G has about $140 \%$ stronger maximum IVT (Figs. 6d-f) and nearly doubled maximum upward motion (Figs. 9a-c). As a result, the AR5-G has a maximum latent heating rate over $14 \mathrm{Kday}^{-1}$ and a maximum low-level PV over $1.1 \mathrm{PVU}$, which are $110 \%$ and $100 \%$ stronger than the NO-AR-G (Fig. 9). Since the AR5-G has larger ETC central deepening rate (Fig. 5b) than both of the NO-AR-G and the AR-G, it suggests that in addition to the existence of an AR, the intensity of an antecedent AR also has great impacts on the ETC deepening.

The large differences of latent heating rate and low-level PV are evident not only in the composite fields as described above but also in the time series through the ETC-genesis stage (Fig. 10b). Although the differences of latent heating rate among the three types of ETC-genesis are not statistically significant at $24 \mathrm{~h}$ before ETC-genesis $(-24 \mathrm{~h})$, starting from $-18 \mathrm{~h}$ the difference becomes larger and statistically significant at the $95 \%$ confidence level. At $-12 \mathrm{~h}$, the latent heating rate of the AR-G and the AR5-G are about $50 \%$ and $110 \%$ stronger than the NO-AR-G, respectively. These significant differences are systematic and persistent from -18 to $+24 \mathrm{~h}$. The result for the time series of low-level PV (not shown) is similar to the latent heating rate in Fig. 10b. These results imply that the large differences of latent heat release and low-level PV are persistent through the ETC-genesis stage, contributing to the difference in ETC deepening.

\section{3) LOW-LEVEL BAROCLINICITY}

Low-level baroclinicity plays an important role in ETCgenesis. The composite temperature gradient at $850 \mathrm{hPa}$ exhibits a maximum $>12 \mathrm{~K}$ per $1000 \mathrm{~km}$ at the north of the 

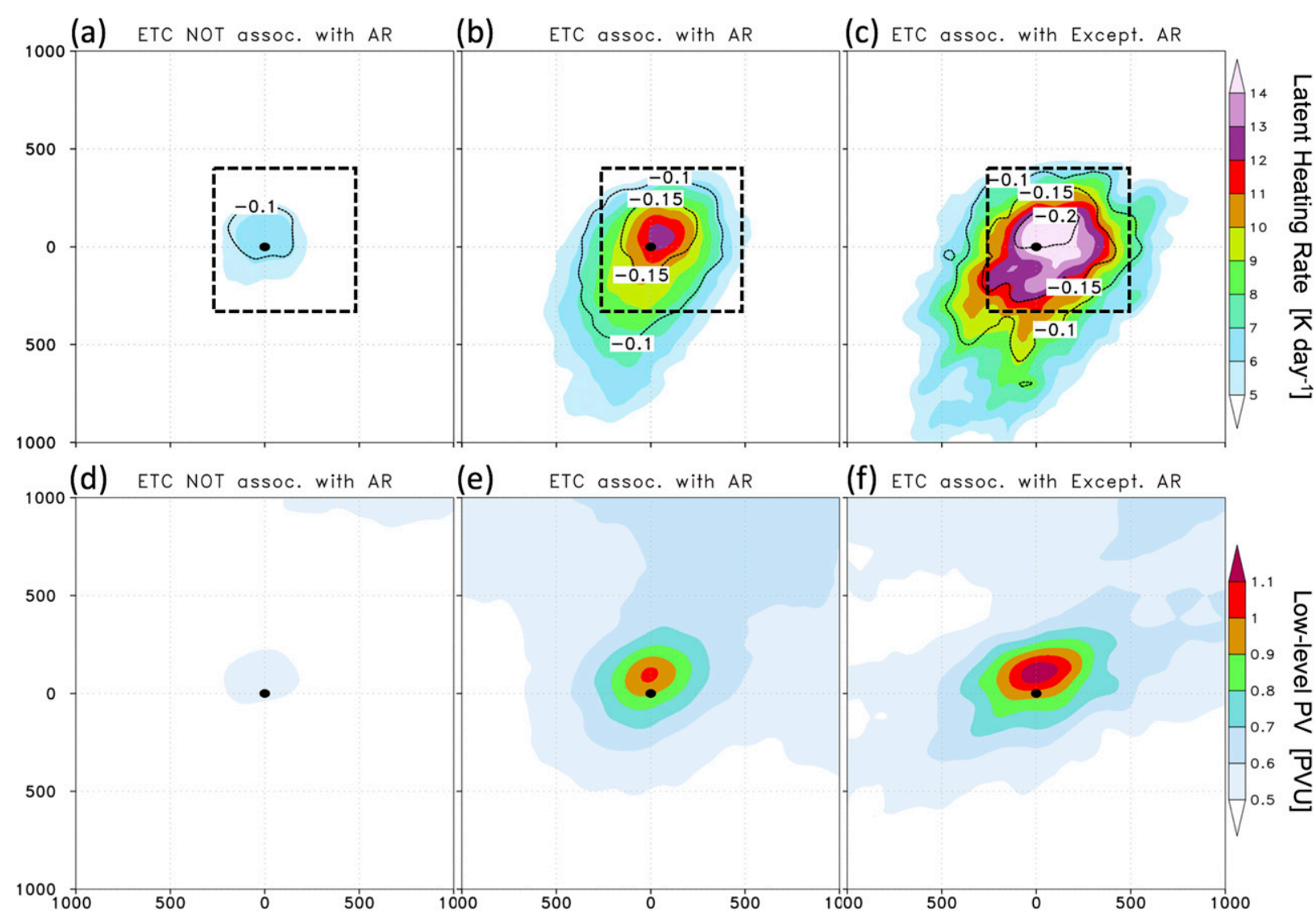

FIG. 9. As in Fig. 6, but for (a)-(c) latent heating rate (colors; $\mathrm{K} \mathrm{day}^{-1}$ ) at $950-500 \mathrm{hPa}$ and vertical motion (omega; contours; $\mathrm{Pa} \mathrm{s}{ }^{-1}$ ) at $700 \mathrm{hPa}$; (d)-(f) 900-750-hPa layer averaged potential vorticity (PV; PVU). The dashed black box in (a)-(c) is used to calculate the mean latent heating rate during cyclogenesis stage.

ETC-genesis point for all of the three types of ETC-genesis (Figs. 11a-c). At almost the same region, the Eady growth rate at $850-500 \mathrm{hPa}$, which is calculated to assess the baroclinic instability, also exhibits a maximum $>1.1 \mathrm{day}^{-1}$ for all the ETC-genesis (Figs. 11a-c). Comparing the AR-G and the NO-AR-G, the intensity and structure of the $850-\mathrm{hPa}$ temperature gradient are very similar. The NO-AR-G even has a slightly $(3 \%-5 \%)$ stronger temperature gradient around the ETC-genesis point, while the AR-G has an amplified meridional structure. Meanwhile, the AR5-G has the same spatial structure of temperature gradient as the AR-G and $5 \%-10 \%$ stronger gradient than the NO-AR-G. The spatial pattern of composite Eady growth rate matches with the pattern of the $850-\mathrm{hPa}$ temperature gradient. The amplitude difference of composite Eady growth rate between the NO-AR-G and the AR-G/AR5-G is also relatively small (Figs. 11d,e). Compared to the NO-AR-G, the AR-G has $5 \%-10 \%$ and the AR5-G has about $10 \%$ stronger Eady growth rate over the north-west side of the ETC-genesis point. The AR-G and the AR5-G have over $10 \%$ weaker Eady growth rate than the NO-AR-G over the southeast of the ETC-genesis point (Figs. 11d,e) which is caused by the amplified meridional structure and is far away from the ETC-genesis point. Overall, the AR-G and the AR5-G have slightly stronger (lower than or close to $10 \%$ ) baroclinic instability than the NO-AR-G.

To further examine the low-level baroclinicity through the ETC-genesis stage, the time series of mean Eady growth rate is calculated within the dashed boxes in Fig. 11, which covers the maximum Eady growth rate for all the ETC-genesis types. The Eady growth rate of the AR-G is only slightly stronger (4\%$7 \%$ ) than the NO-AR-G (Fig. 13a). Meanwhile, the Eady growth rate of the AR5-G is 3\%-8\% stronger than the AR-G through the ETC-genesis stage. All of these differences are not statistically significant at the $95 \%$ confidence level though the ETC-genesis stage, indicating that the low-level baroclinicity is not a critical factor controlling the difference of the deepening rate between the three ETC-genesis categories.

\section{4) UPPER-LEVEL FORCING}

The upper-level forcing is another important factor contributing to ETC-genesis. Figures $12 \mathrm{a}-\mathrm{c}$ shows the composite mean upper-level PV and jet in the $24 \mathrm{~h}$ before ETC-genesis. As expected, all three types of ETC-genesis have a strong tropopause-based cyclonic PV over the north-west of the ETCgenesis point. Comparing to the NO-AR-G, the upper-level $\mathrm{PV}$ of the AR-G has a $\sim 8 \%$ stronger maximum over the northwest (dashed box) of the ETC-genesis point and exhibits 

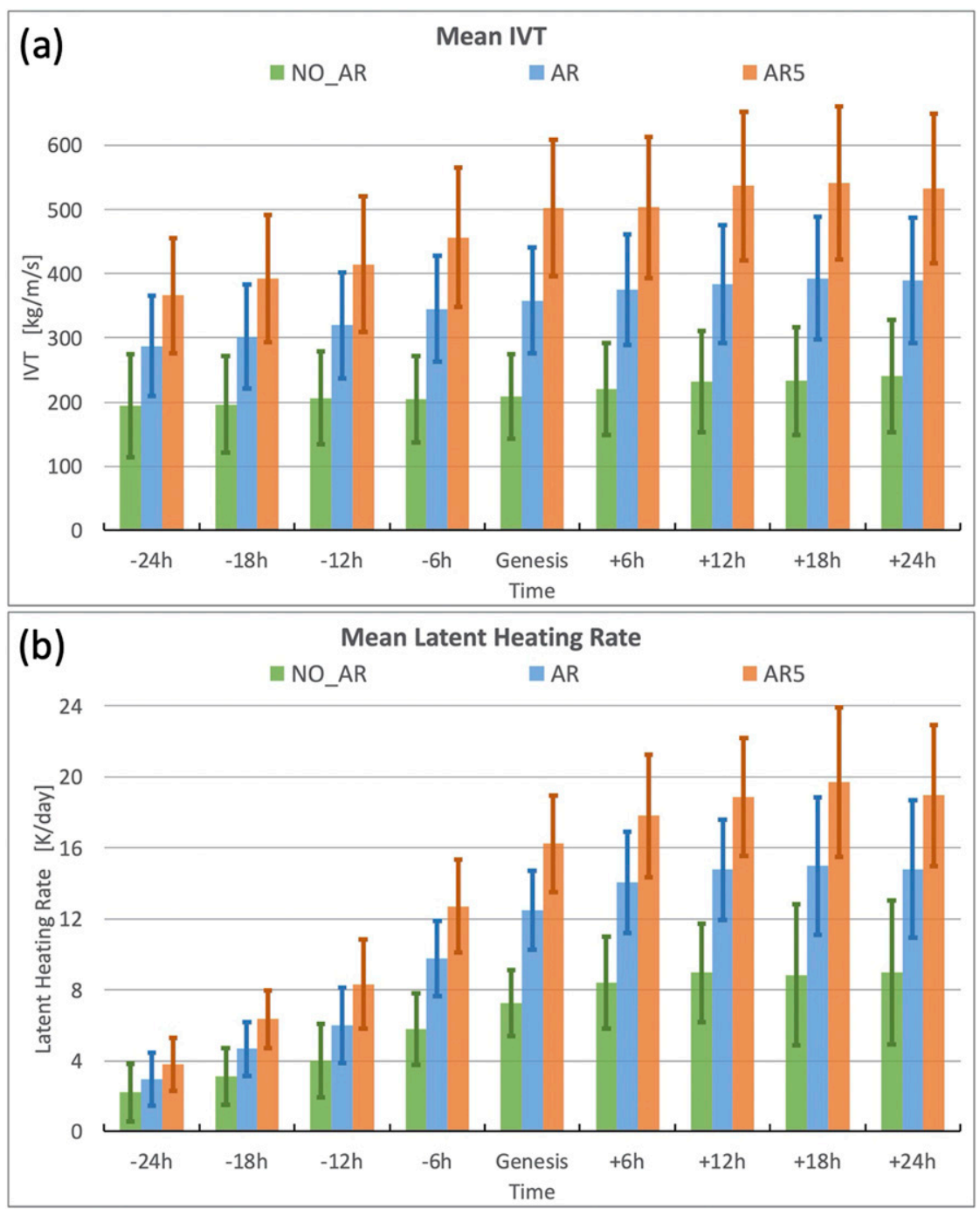

FIG. 10. (a) Time series of mean IVT $\left(\mathrm{kg} \mathrm{m}^{-1} \mathrm{~s}^{-1}\right)$ within the dashed black box in Fig. 6 from $24 \mathrm{~h}$ before $(-24 \mathrm{~h})$ to $24 \mathrm{~h}$ after $(+24 \mathrm{~h})$ cyclogenesis for the cases not associated with an antecedent AR (green), associated with an antecedent AR (blue), and associated with an antecedent exceptional AR (red). The vertical bars denote the spread (one standard deviation) of mean IVT at each time step. (b) As in (a), but for mean latent heating rate $\left(\mathrm{K} \mathrm{day}^{-1}\right)$ within the dashed black box in Fig. 9.

an amplified meridional structure. The upper-level PV of the NO-AR-G exhibits a similar amplified meridional structure starting from $6 \mathrm{~h}$ before ETC-genesis (e.g., upper-level PV at the ETC-genesis time point in Fig. 15a). Meanwhile, the composite upper-level PV of the AR5-G is similar to the AR-G both in terms of structure and amplitude. In addition to the composite field, the time series of upper-level PV through the ETC-genesis stage is calculated and shown in Fig. 13b. For the upper-level PV, the AR-G is $4 \%-9 \%$ stronger than the NO-AR-G through the ETC-genesis stage, while the AR5-G is very close to the AR-G (difference $<5 \%$ ). These differences of upper-level PV are not statistically significant at the $95 \%$ confidence level.

The stratification of atmosphere is also important on affecting ETC-genesis and it may modulate the influence of upper-level PV. The static stability here is quantified using the square of Brunt-Väisälä (BV) frequency at $850-500 \mathrm{hPa}$, which is calculated following Durran and Klemp (1982). All of the three types of ETC-genesis have similar spatial pattern of the BV frequency with an unstable (low BV frequency) area around the ETC-genesis point and its west-northwest in the $24 \mathrm{~h}$ before ETC-genesis (Figs. 12d-f). The AR-G has a more unstable center ( $\sim 6 \%$ lower in squared $\mathrm{BV}$ frequency) compared to the NO-AR-G. Meanwhile, the squared BV frequency value of the AR5-G is very close to the AR-G (difference $<5 \%$ ) but with a slightly amplified meridional structure. Overall, the differences of static stability and upperlevel PV between the three types of ETC-genesis are relatively small, around $5 \%$ in amplitude. 


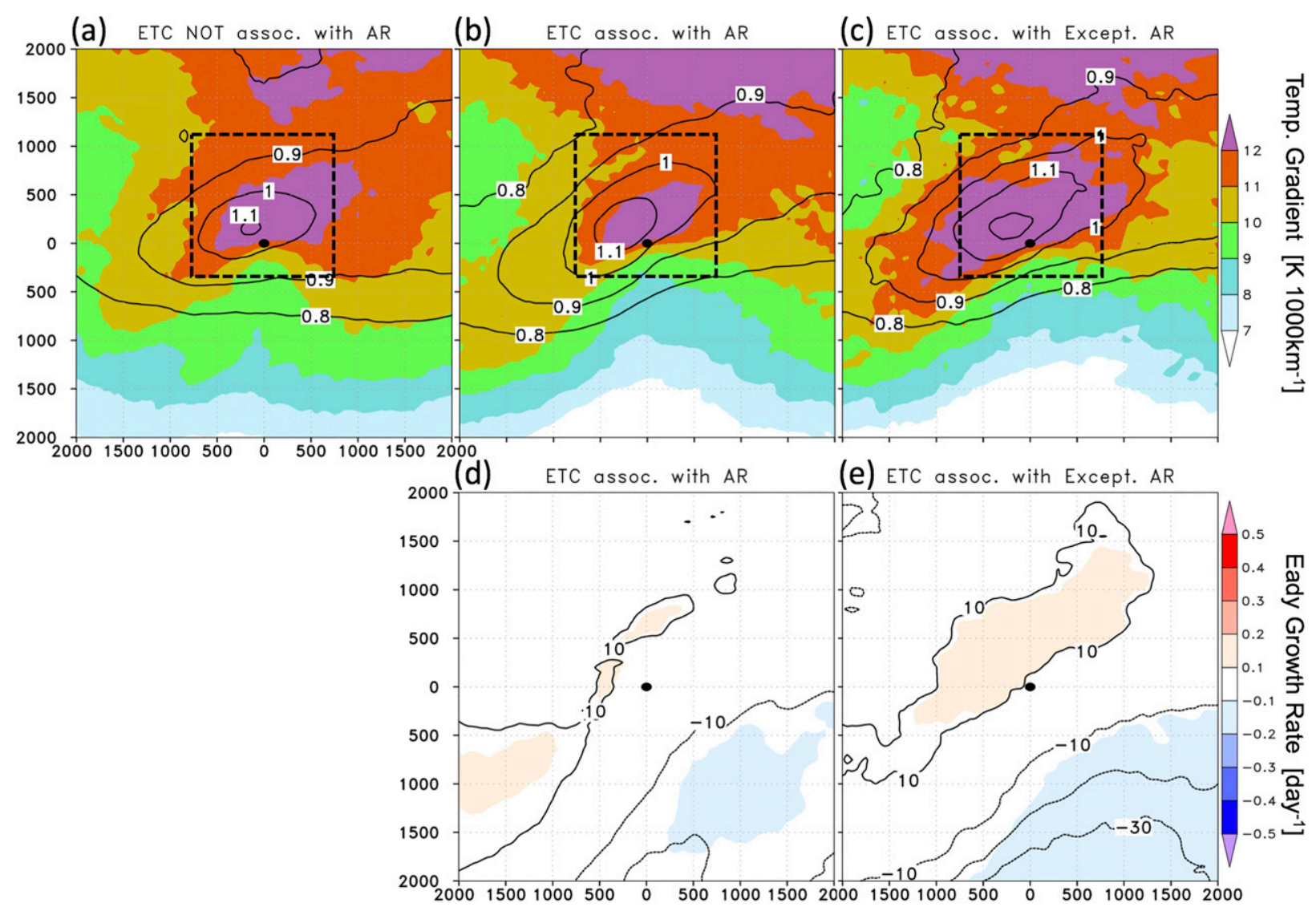

FIG. 11. (a)-(c) As in Fig. 6, but for temperature gradient [colors; K $(1000 \mathrm{~km})^{-1}$ ] at $850 \mathrm{hPa}$ and Eady growth rate $\left(\right.$ contours; day $\left.{ }^{-1}\right)$ at $850-500 \mathrm{hPa}$. The dashed black box in (a)-(c) is used to calculate mean Eady growth rate during cyclogenesis stage. (d) The difference of Eady growth rate (colors, day ${ }^{-1}$; contours, \%) between cyclogenesis associated with an antecedent AR and not associated with an antecedent AR [(b) minus (a)]; only the differences at statistical confidence level 95\% are plotted. (e) As in (d), but for the difference between cyclogenesis associated with an exceptional AR and not associated with an AR [(c) minus (a)].

The composite upper-level jet for ETC-genesis matches their upper-level PV fields as shown in Fig. 12. The ETCgenesis points of the NO-AR-G, the AR-G, and the AR5-G are all located at the left side of the upper-level jet exit, which is a region of upper-level divergence and favorable to the upward motion and the decrease of surface pressure. Compared to the NO-AR-G $\left(40 \mathrm{~m} \mathrm{~s}^{-1}\right)$, the jet core of the AR-G $\left(44 \mathrm{~m} \mathrm{~s}^{-1}\right)$ is $10 \%$ stronger with an amplified meridional structure. Meanwhile, the upper-level jet of the AR5-G is similar to the AR-G, but the jet core is slightly stronger $(\sim 7 \%)$ than the AR-G. The stronger upper-level jet for the AR-G and the AR5-G intensifies the upward motion, which is favorable to precipitation and latent heat release.

\section{5) SUMMARY}

The time series of IVT, latent heating rate, Eady growth rate, and upper-level PV in Figs. 10 and 13 demonstrate the differences of the critical diabatic and dry dynamical factors controlling the three different types of ETC-genesis. Figure 14 shows the normalized percentage differences for the AR-G and the AR5-G with respect to the NO-AR-G based on the time series in Figs. 10 and 13. It is clear that the differences of dry dynamical factors, including Eady growth rate and upperlevel PV (Figs. 14a,c), are very small between the AR-G/AR5-G and the NO-AR-G, especially before ETC-genesis (below or close to $10 \%$ ). Additionally, those differences are not statistically significant as previously described. In contrast, the differences of IVT $(55 \%-80 \%)$ and latent heating rate $(45 \%-80 \%)$ between the AR-G and the NO-AR-G are much larger and statistically significant at the $95 \%$ confidence level for most of those time steps (Figs. 14b,d). It indicates that while the dry dynamics are comparable, an antecedent AR provides significantly stronger water vapor inflow to the ETC-genesis than the cases without an AR, enhancing the latent heat release and lowlevel PV (Fig. 9e), which can intensify the ETC deepening in the ETC-genesis stage.

Meanwhile, the differences in IVT (90\%-140\%) and latent heating rate $(70 \%-125 \%)$ between the AR5-G and the NO-AR-G are even larger and statistically significant at all time steps (Fig. 14). In other words, the AR5-G has stronger water vapor inflow and latent heat release than both of the NO-AR-G and the AR-G. These results imply that the intensity of an antecedent AR can modulate the ETC deepening rate during the ETC-genesis stage. 

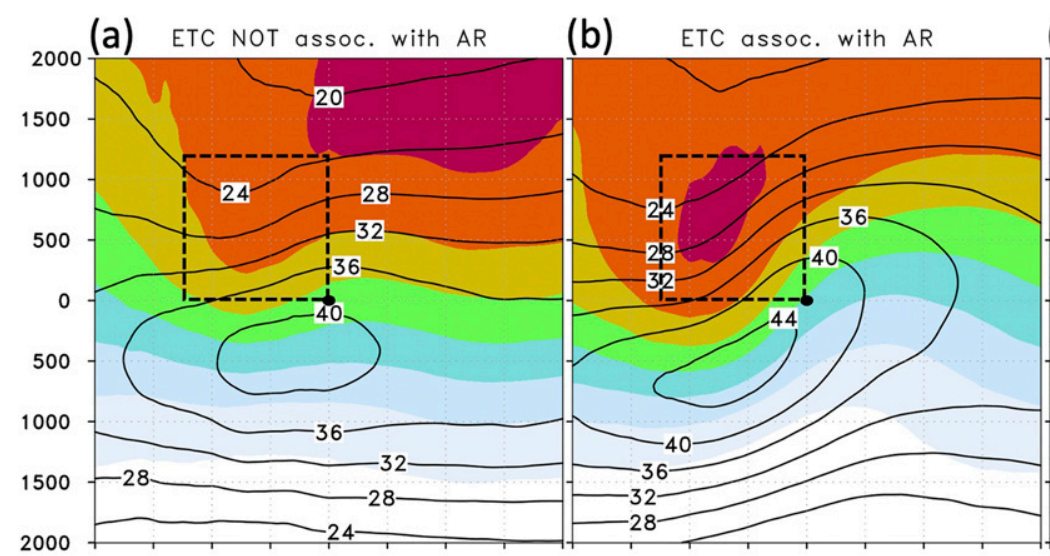

(c) ETC assoc. with Except. AR

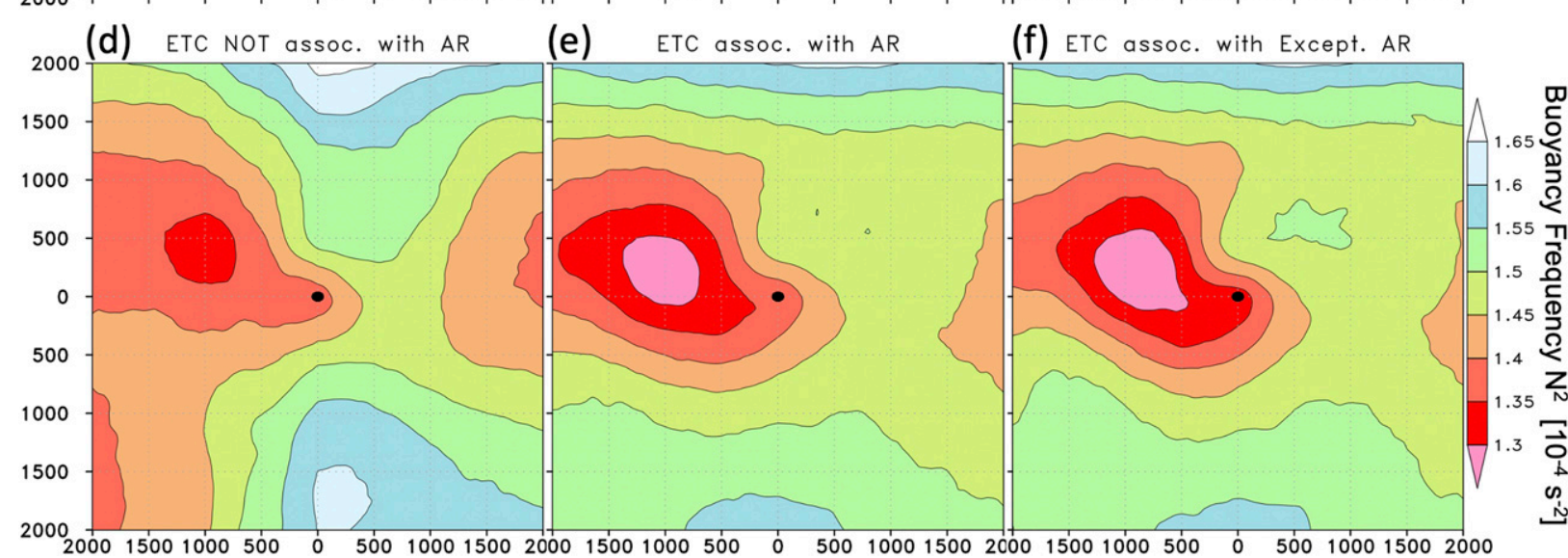

FIG. 12. (a)-(c) As in Fig. 6, but for upper-level (300-200 hPa) PV (colors; PVU) and 300-hPa wind speed (colors; $\mathrm{m} \mathrm{s}^{-1}$ ). The dashed black box is used to calculate mean upper-level PV during cyclogenesis stage. (d)-(f) As in Fig. 6, but for the square of Brunt-Väisälä (BV) frequency (colors; $\times 10^{-4} \mathrm{~s}^{-2}$ ).

Figure 15 is a schematic summary to compare the ETCgenesis with and without an antecedent $\mathrm{AR}$, including the ETC-genesis time as well as $24 \mathrm{~h}$ after that. The relevant fields in the schematic were plotted according to the corresponding composite fields of the ETC-genesis cases with an antecedent AR (1088 cases) and without an antecedent AR (2049 cases) in the 31 cool seasons over the North Pacific region. At the ETCgenesis time point, the first closed SLP is $1010 \mathrm{hPa}$ for the NO-AR-G and $1006 \mathrm{hPa}$ for the AR-G. Meanwhile the AR-G includes nearly $80 \%$ more water vapor inflow, $10 \%$ stronger upper-level jet, and similar (difference $<10 \%$ ) upper-level PV and low-level baroclinicity. After $24 \mathrm{~h}$, the ETC central SLP is $1002 \mathrm{hPa}$ for the NO-AR-G (deepened $7.7 \mathrm{hPa}$ ) and $994 \mathrm{hPa}$ for the AR-G (deepened $11.6 \mathrm{hPa}$ ). The ETC-genesis cases associated with an antecedent AR deepens $\sim 50 \%$ faster on average than the events without an AR in the $24 \mathrm{~h}$ after ETCgenesis.

\section{Conclusions and discussion}

This study investigates the influence of antecedent atmospheric river (AR) conditions on extratropical cyclogenesis (ETC-genesis) over the North Pacific in cool seasons (November-March). Although many previous studies considered
$\mathrm{AR}$ as a portion of an extratropical cyclone (ETC) or emphasized the creation of ARs by ETCs (e.g., Bao et al. 2006; Neiman et al. 2008; Dacre et al. 2015), this study explores how often an antecedent AR exists at the time of ETC-genesis and how such an AR can affect the ensuing ETC-genesis. To comprehensively and quantitively investigate the influence of ARs on ETC-genesis, an automated ETC tracking algorithm was used to identify all ETC-genesis cases (total 3137) over the North Pacific (between $120^{\circ} \mathrm{E}-115^{\circ} \mathrm{W}$ and $25^{\circ}-65^{\circ} \mathrm{N}$, Fig. 3) during 31 cool seasons (1979-2009). These ETC-genesis cases were categorized into three types: ETC-genesis not associated with an antecedent $\mathrm{AR}$, associated with an antecedent $\mathrm{AR}$, and associated with an antecedent AR of exceptional intensity as described in section $3 \mathrm{a}$.

The results of this study are summarized in a schematic (Fig. 15) that uses composite fields from 3137 ETC-genesis events to compare ETC-genesis with and without an antecedent AR. It includes a comparison of the conditions at the initial time of ETC-genesis as well as $24 \mathrm{~h}$ later. Overall, $34.7 \%$ of the ETC-genesis cases were associated with an antecedent AR over the North Pacific in the cool season (AR-G in Table 1). However, this percentage varies regionally. Over the major ETC-genesis area in the western North Pacific (blue box in Fig. 3a), 31.5\% of ETC-genesis cases include an antecedent 

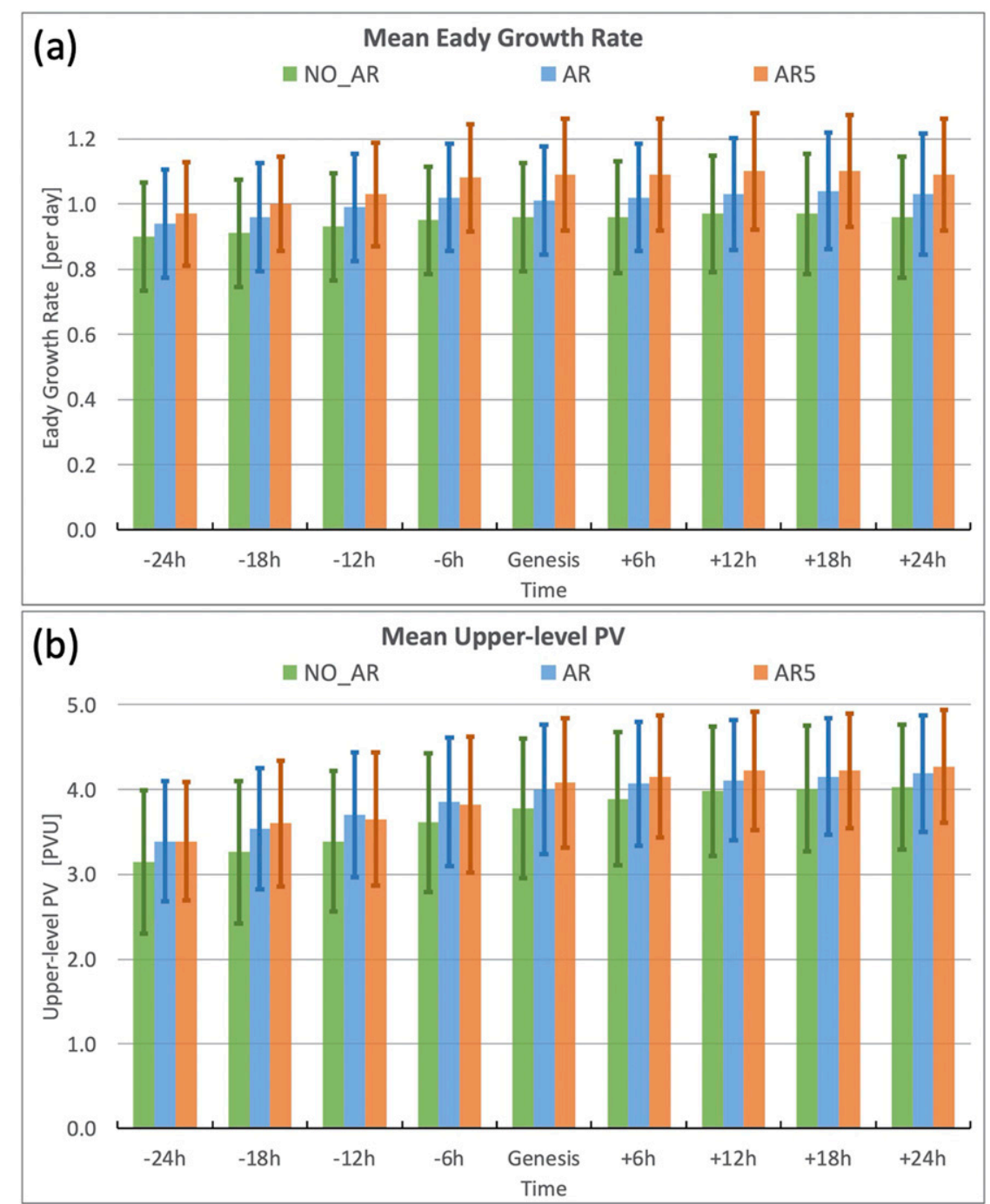

FIG. 13. As in Fig. 10, but for (a) mean Eady growth rate $\left(\right.$ day $\left.^{-1}\right)$ at $850-500 \mathrm{hPa}$ within the dashed black box in Fig. 11; (b) mean upper-level (300-200 hPa) PV (PVU) within the dashed black box in Fig. 12.

AR. In contrast, over the eastern North Pacific (red box in Fig. 3a) with relatively more water vapor available, $55.0 \%$ of ETC-genesis cases include an antecedent AR. Before or at the ETC-genesis time, when the low-level cyclonic circulation is weak, an anticyclone over the southeast side of ETC-genesis location is critical, which can intensify the sea level pressure gradient and the low-altitude southwest wind (Figs. 6-8). If there is enough water vapor in this airstream, the region may thus constitute an antecedent AR at ETC-genesis. Over the eastern North Pacific region (red box in Fig. 3a), the relatively high water vapor content and the North Pacific high provide favorable conditions for these cases.

The ETC-genesis events with an antecedent AR develop more rapidly with larger deepening rate in the $24 \mathrm{~h}$ after ETCgenesis (Figs. 4,5,6a-c; Fig. 15). Although only $34.7 \%$ of all ETC-genesis cases include an antecedent AR, they contribute about $60 \%$ of the explosive ETC-genesis (central pressure decreases at least $24 \mathrm{hPa}$ in the $24 \mathrm{~h}$ after ETC-genesis). In addition, the ETC-genesis cases with an antecedent AR of exceptional intensity tend to develop even more rapidly than the ETC-genesis with an antecedent AR of average intensity (Figs. 5 and $6 \mathrm{a}-\mathrm{c}$ ). Thus, the existence and the intensity of an antecedent AR significantly impacts the ensuing ETC deepening after ETC-genesis.

On average, ETC-genesis cases with an antecedent AR include up to $80 \%$ greater water vapor inflow into the developing ETC (Figs. 6 and 10a; Fig. 15). This fuels up to $80 \%$ greater latent heat release during cloud and precipitation formation through the ETC-genesis stage (from $24 \mathrm{~h}$ before to $24 \mathrm{~h}$ after ETC-genesis), resulting in about $80 \%$ stronger low-level diabatic PV close to the ETC center (Figs. 9 and 10b; Fig. 15). Additionally, ETC-genesis cases with an antecedent AR of exceptional intensity (an AR with maximum IVT $>1250 \mathrm{~kg} \mathrm{~m}^{-1} \mathrm{~s}^{-1}$, AR5 per Ralph et al. 2019) has up to $140 \%$ greater water vapor 

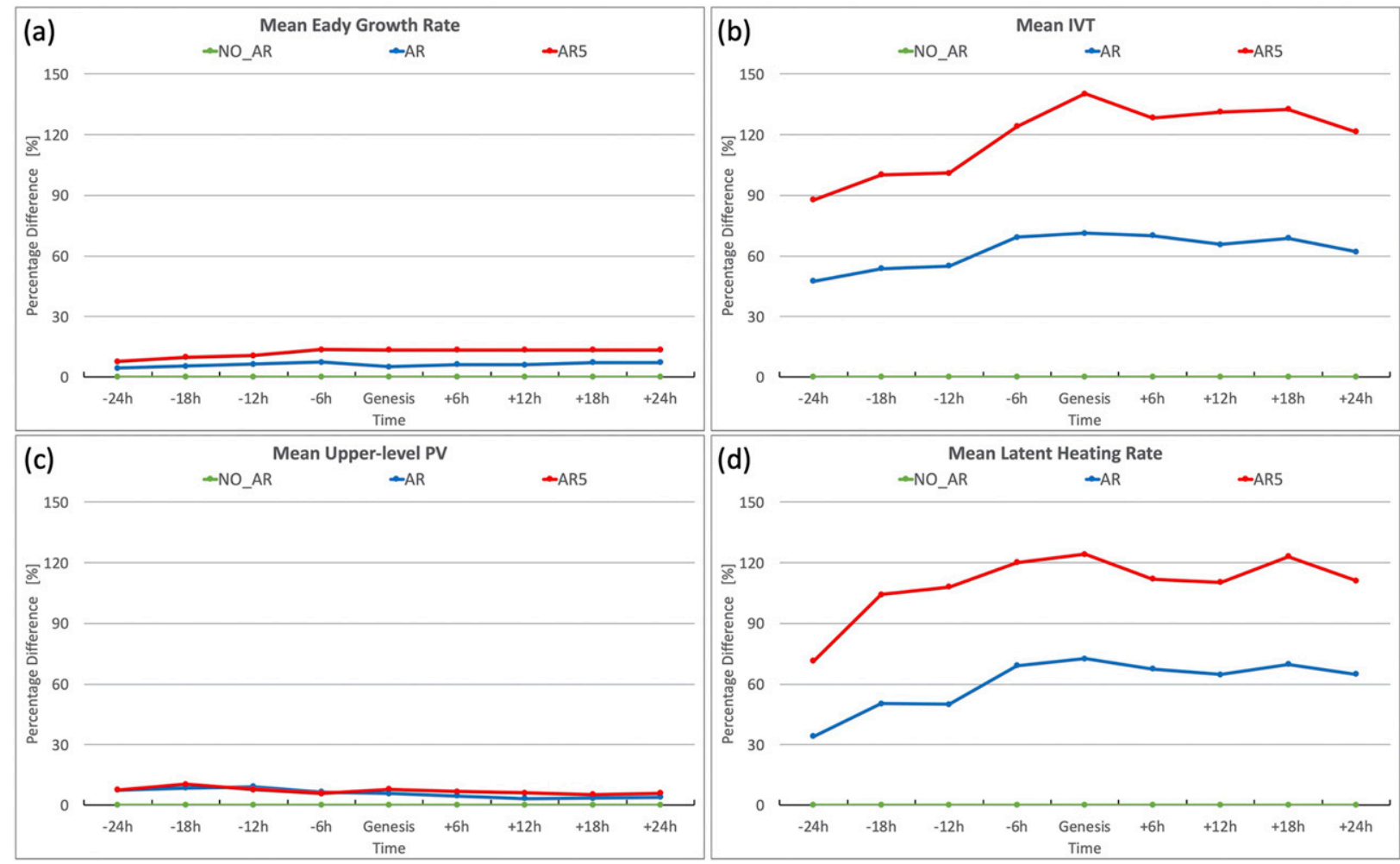

FIG. 14. (a) Normalized difference (\%, with respect to the value of cyclogenesis not associated with an antecedent AR) of mean Eady growth rate within the dashed black box in Fig. 11 for cyclogenesis associated with an antecedent AR (blue) and an antecedent exceptional AR (red) from $24 \mathrm{~h}$ before $(-24 \mathrm{~h})$ to $24 \mathrm{~h}$ after $(+24 \mathrm{~h})$ cyclogenesis. (b) $-(\mathrm{d})$ As in (a), but for the normalized difference of mean IVT, upper-level PV, and latent heating rate, respectively.

inflow, resulting in up to $125 \%$ stronger latent heat release. These differences are statistically significant at the $95 \%$ confidence level at nearly all of the time steps through the ETC-genesis stage. In contrast, the differences of low-level baroclinicity and upper-level PV remain close to or smaller than $10 \%$ across the three types of ETC-genesis and most of those differences are not statistically significant through the ETC-genesis stage (Figs. 11-13 and 14a,c). The upper-level jet of the ETC-genesis events with an antecedent AR (of exceptional intensity) is about $10 \%(18 \%)$ stronger than the ETCgenesis without an AR. However, the differences in terms of diabatic processes are significantly larger than those in terms of jet strength. It indicates that diabatic processes, fueled by an antecedent $\mathrm{AR}$, is the primary factor controlling the differences between deepening rates of the three types of ETCgenesis. When the other factors (low-level baroclinicity and upper-level forcing) are similar, the existence and the intensity of an antecedent AR are of critical importance to the ETC deepening in the ETC-genesis stage.

This study is closely related to the previous studies regarding the contribution of the diabatic process to ETC intensification based on warm conveyor belt (WCB, Wernli and Davies 1997; Madonna et al. 2014; Binder et al. 2016). However, this study highlights the influence of antecedent AR condition on the ETC deepening during the ETC-genesis stage. An antecedent AR provides extra water vapor inflow to the ascending airstream that is very likely associated with WCB over the warm sector of ETC-genesis (Figs. 6e,f and 9b,c), and then intense latent heat release and low-level PV production occur (Fig. 9), intensifying the ETC deepening. The similarity in some composite fields in this study and Binder et al. (2016) implies the strong link between AR and WCB.

This study improves the understanding of ETC-genesis, including rapid ETC-genesis. It elucidates the vital role of antecedent horizontal water vapor transport, as delineated by the existence and intensity of an antecedent AR. The influence of antecedent ARs on ETC-genesis can be summarized as follows: First, the low-level baroclinicity and upper-level forcing are essential to ETC-genesis. For all of the three types of ETCgenesis, the low-level baroclinicity, upper-level PV, and upperlevel jet exhibit favorable spatial patterns and strong amplitude in $24 \mathrm{~h}$ before ETC-genesis (Figs. 11-13). However, an antecedent AR can provide extra fuel (nearly $80 \%$ more water vapor inflow) to significantly enhance the diabatic process, which on average intensifies the ETC's deepening rate by $\sim 50 \%$ in the $24 \mathrm{~h}$ after ETC-genesis. These conclusions are consistent with a recent study from Graf et al. (2017), who used an objective statistical technique to classify ETC-genesis. They found that many well-known high-impact ETC-genesis events (most of them are explosive ETC-genesis) fall within two classes characterized by strong low-level moist processes with or without strong upper-level forcing. 


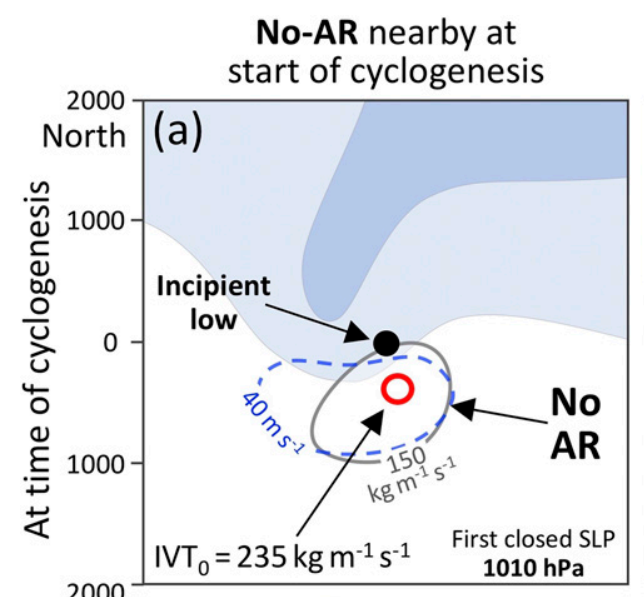

\section{An AR is nearby at start of cyclogenesis}
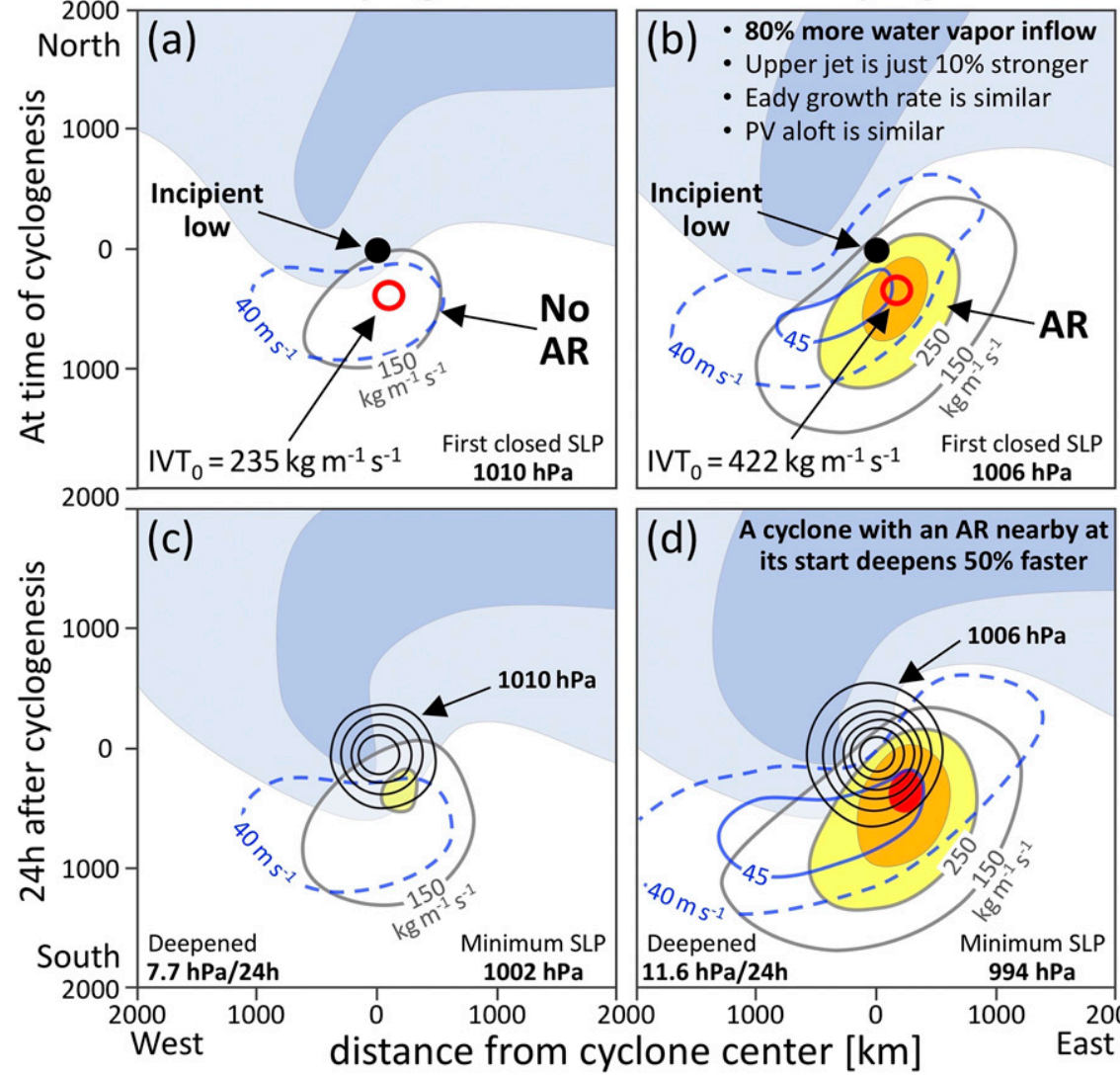

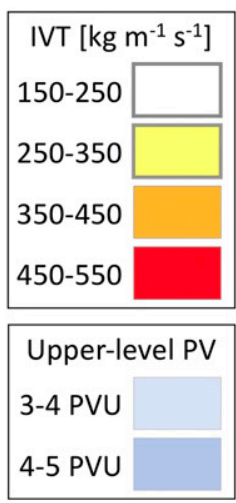

Upper-level jet - - . $40 \mathrm{~m} \mathrm{~s}^{-1}$ $45 \mathrm{~m} \mathrm{~s}^{-1}$

Sea Level Pressure - every $2 \mathrm{hPa}$

Incipient low-

pressure center at cyclogenesis

IVT: Max IVT

$\mathrm{O}$ at time of cyclogenesis

FIG. 15. Schematic summary of the cyclogenesis (a),(c) not associated with an antecedent AR and (b),(d) associated with an antecedent AR at (top) the time of cyclogenesis and (bottom) $24 \mathrm{~h}$ after cyclogenesis. The structures and magnitudes of IVT (gray contour; yellow, orange, and red), upper-level PV (300-200 hPa; light blues), upper-level jet ( $300 \mathrm{hPa}$; dashed and solid blue contours), and SLP (every $2 \mathrm{hPa}$; black contours) are based on the corresponding composite fields of cyclogenesis cases over the North Pacific in 31 (1979-2009) cool seasons from CFSR. In (a) and (b), the red circle denotes the position of maximum IVT, and the black dot denotes the position of incipient low pressure center at the time of cyclogenesis. In (c) and (d), the closed SLP contours start from the first closed SLP at the time of cyclogenesis not associated with an antecedent AR $(1010 \mathrm{hPa})$ and associated with an antecedent AR $(1006 \mathrm{hPa})$, respectively.

In the eastern North Pacific, over half of the ETC-genesis cases are associated with an antecedent AR. Those quick developing events are very close to the U.S. West Coast and potentially have high impacts on that region (e.g., Martin et al. 2019). After traditional baroclinic instability and upper-level forcing initiates ETC-genesis, those developing ETCs that also have ready access to large amounts of water vapor (in the form of an AR in the optimal location relative to the center of the nascent ETC) are far more likely to develop explosive deepening rates. In short, the presence of an AR sets the stage for much greater latent heat release within the $\mathrm{WCB}$, which then amplifies the ETC's intensification rate. Because the location of initial baroclinic ETC-genesis can be somewhat independent of whether or not an AR happens to be in the right location as deepening begins, this aspect of the initial condition could prove vital in determining the ETC deepening rate. This implies forecast skill may be very sensitive to the presence of an AR and to its detailed characteristics relative to the location of the initial (dry dynamics) ETC-genesis. This inference is consistent with recent results from studies of initial condition error sensitivity using an adjoint model that includes the diabatic effects of moisture and found that on average the location of greatest sensitivity to initial condition uncertainty for highimpact west-coast landfalling ARs is the AR itself offshore (Reynolds et al. 2019). Demirdjian et al. (2020) diagnosed that this sensitivity resulted partly from the role of water vapor in the AR on modulating latent heating and vertical circulations. Additionally, Lavers et al. (2018, 2020) used dropsondes from the airborne AR reconnaissance program (Ralph et al. 2020b) to show that significant initial condition errors exist in ARs in the European Centre for Medium-Range Weather Forecasts (ECMWF) model. Although this study and those cited here indicate the importance of accurate initial conditions in and near an AR offshore, Zheng et al. (2021) identified a data gap 
in the lower part of the atmosphere under AR conditions based on the assimilated observations in the NCEP Global Forecast System (GFS) model.

In short, the finding of this paper that the presence and intensity of an antecedent AR in an ETC-genesis event strongly impacts the strength of the deepening, reinforces the importance of ensuring global weather prediction models are initialized with accurate representations of ARs in their initial conditions, including the unique AR-targeted observations provided by AR reconnaissance (Ralph et al. 2020b).

Acknowledgments. Support for this work was provided by the U.S. Army Corps of Engineers "Forecast-Informed Reservoir Operations" Program and the California Department of Water Resources "Atmospheric Rivers Program."

Data availability statement. The NCEP CFSR data used in this study is obtained from the Research Data Archive at the National Center for Atmospheric Research (https:// rda.ucar.edu/).

\section{REFERENCES}

Ahmadi-Givi, F., G. C. Graig, and R. S. Plant, 2004: The dynamics of a midlatitude cyclone with very strong latent-heat release. Quart. J. Roy. Meteor. Soc., 130, 295-323, https://doi.org/ 10.1256/qj.02.226.

Bao, J. W., S. A. Michelson, P. J. Neiman, F. M. Ralph, and J. M. Wilczak, 2006: Interpretation of enhanced integrated water vapor bands associated with extratropical cyclones: Their formation and connection to tropical moisture. Mon. Wea. Rev., 134, 1063-1080, https://doi.org/10.1175/MWR3123.1.

Binder, H., M. Boettcher, H. Joos, and H. Wernli, 2016: The role of warm conveyor belts for the intensification of extratropical cyclones in Northern Hemisphere winter. J. Atmos. Sci., 73, 3997-4020, https://doi.org/10.1175/JAS-D-15-0302.1.

Bjerknes, J., 1919: On the structure of moving cyclones. Mon. Wea. Rev., 47, 95-99, https://doi.org/10.1175/1520-0493(1919)47<95: OTSOMC $>2.0 . \mathrm{CO} ; 2$.

Browning, K. A., 1990: Organization of clouds and precipitation in extratropical cyclones. Extratropical Cyclones: The Erik Palmén Memorial Volume, C. W. Newton and E. O. Holopainen, Eds., Amer. Meteor. Soc., 129-153.

Chang, C. B., D. J. Perkey, and C. W. Kreitzberg, 1984: Latent heat induced energy transformations during cyclogenesis. Mon. Wea. Rev., 112, 357-367, https://doi.org/10.1175/15200493(1984)112<0357:LHIETD>2.0.CO;2.

Colle, B. A., Z. Zhang, K. A. Lombardo, E. Chang, P. Liu, and M. Zhang, 2013: Historical evaluation and future prediction of eastern North American and western Atlantic extratropical cyclones in the CMIP5 models during the cool season. J. Climate, 26, 6882-6903, https://doi.org/10.1175/JCLI-D-1200498.1.

Cordeira, J. M., F. M. Ralph, and B. J. Moore, 2013: The development and evolution of two atmospheric rivers in proximity to western North Pacific tropical cyclones in October 2010. Mon. Wea. Rev., 141, 4234-4255, https://doi.org/10.1175/MWR-D-13-00019.1.

Dacre, H. F., 2020: A review of extratropical cyclones: Observations and conceptual models over the past 100 years. Weather, 75, 4-7, https://doi.org/10.1002/wea.3653.

—, P. A. Clark, O. Martinez-Alvarado, M. A. Stringer, and D. A. Lavers, 2015: How do atmospheric rivers form? Bull. Amer.
Meteor. Soc., 96, 1243-1255, https://doi.org/10.1175/BAMS-D14-00031.1.

O. Martinez-Alvarado, and C. O. Mbengue, 2019: Linking atmospheric rivers and warm conveyor belt airflows. J. Hydrometeor., 20, 1183-1196, https://doi.org/ 10.1175/JHM-D-18-0175.1.

Danard, M. B., 1964: On the influence of released latent heat on cyclone development. J. Appl. Meteor., 3, 27-37, https://doi.org/ 10.1175/1520-0450(1964)003<0027:OTIORL>2.0.CO;2.

Davis, C. A., and K. A. Emanuel, 1991: Potential vorticity diagnostics of cyclogenesis. Mon. Wea. Rev., 119, 1929-1953, https:// doi.org/10.1175/1520-0493(1991)119<1929:PVDOC>2.0.CO;2.

Debbage, N., P. Miller, S. Poore, K. Morano, T. Mote, and J. Marshall Shepherd, 2017: A climatology of atmospheric river interactions with the southeastern United States coastline. Int. J. Climatol., 37, 4077-4091, https://doi.org/10.1002/ joc.5000.

Demirdjian, R., J. D. Doyle, C. A. Reynolds, J. R. Norris, A. C. Michaelis, and F. M. Ralph, 2020: A case study of the physical processes associated with the atmospheric river initial condition sensitivity from an adjoint model. J. Atmos. Sci., 77, 691709, https://doi.org/10.1175/JAS-D-19-0155.1.

Dettinger, M., 2011: Climate change, atmospheric rivers, and floods in California-A multimodel analysis of storm frequency and magnitude changes. J. Amer. Water Resour. Assoc., 47, 514523, https://doi.org/10.1111/j.1752-1688.2011.00546.x.

Diaconis, P., and B. Efron, 1983: Computer-intensive methods in statistics. Sci. Amer., 248, 116-131, https://doi.org/10.1038/ scientificamerican0583-116.

Durran, D. R., and J. B. Klemp, 1982: On the effects of moisture on the Brunt-Väisälä frequency. J. Atmos. Sci., 39, 2152-2158, https:// doi.org/10.1175/1520-0469(1982)039<2152:OTEOMO>2.0.CO;2.

Eiras-Barca, J., A. M. Ramos, J. G. Pinto, R. M. Trigo, M. L. Liberato, and G. Miguez-Macho, 2018: The concurrence of atmospheric rivers and explosive cyclogenesis in the North Atlantic and North Pacific basins. Earth Syst. Dyn., 9, 91-102, https://doi.org/10.5194/esd-9-91-2018.

Emanuel, K. A., M. Fantini, and A. J. Thorpe, 1987: Baroclinic instability in an environment of small stability to slantwise moist convection. Part I: Two-dimensional models. J. Atmos. Sci., 44, 1559-1573, https://doi.org/10.1175/1520-0469(1987) 044<1559:BIIAEO>2.0.CO;2.

Gershunov, A., T. Shulgina, F. M. Ralph, D. A. Lavers, and J. J. Rutz, 2017: Assessing the climate-scale variability of atmospheric rivers affecting western North America. Geophys. Res. Lett., 44, 7900-7908, https://doi.org/10.1002/2017GL074175.

Graf, M. A., H. Wernli, and M. Sprenger, 2017: Objective classification of extratropical cyclogenesis. Quart. J. Roy. Meteor. Soc., 143, 1047-1061, https://doi.org/10.1002/qj.2989.

Guan, B., and D. E. Waliser, 2015: Detection of atmospheric rivers: Evaluation and application of an algorithm for global studies. J. Geophys. Res. Atmos., 120, 12 514-12 535, https://doi.org/ 10.1002/2015JD024257.

—, N. P. Molotch, D. E. Waliser, E. J. Fetzer, and P. J. Neiman, 2010: Extreme snowfall events linked to atmospheric rivers and surface air temperature via satellite measurements. Geophys. Res. Lett., 37, L20401, https://doi.org/10.1029/ 2010GL044696.

, D. E. Waliser, N. P. Molotch, E. J. Fetzer, and P. J. Neiman, 2012: Does the Madden-Julian oscillation influence wintertime atmospheric rivers and snowpack in the Sierra Nevada? Mon. Wea. Rev., 140, 325-342, https://doi.org/10.1175/MWRD-11-00087.1. 
Hirata, H., R. Kawamura, M. Kato, and T. Shinoda, 2016: Response of rapidly developing extratropical cyclones to sea surface temperature variations over the western KuroshioOyashio confluence region. J. Geophys. Res. Atmos., 121, 3843-3858, https://doi.org/10.1002/2015JD024391.

Hodges, K. I., 1994: A general method for tracking analysis and its application to meteorological data. Mon. Wea. Rev., 122, 2573-2586, https://doi.org/10.1175/1520-0493(1994)122<2573: AGMFTA $>2.0 . \mathrm{CO} ; 2$.

_ 1995: Feature tracking on the unit sphere. Mon. Wea. Rev., 123, 3458-3465, https://doi.org/10.1175/1520-0493(1995)123<3458: FTOTUS $>2.0 . \mathrm{CO} ; 2$.

- , R. W. Lee, and L. Bengtsson, 2011: A comparison of extratropical cyclones in recent reanalyses ERA-Interim, NASA MERRA, NCEP CFSR, and JRA-25. J. Climate, 24, 48884906, https://doi.org/10.1175/2011JCLI4097.1.

Hoskins, B. J., and P. J. Valdes, 1990: On the existence of stormtracks. J. Atmos. Sci., 47, 1854-1864, https://doi.org/10.1175/ 1520-0469(1990)047<1854:OTEOST>2.0.CO;2.

-_, and K. I. Hodges, 2002: New perspectives on the Northern Hemisphere winter storm tracks. J. Atmos. Sci., 59, 1041-1061, https://doi.org/10.1175/1520-0469(2002)059<1041: NPOTNH $>2.0 . \mathrm{CO} ; 2$.

— M. E. McIntyre, and A. W. Robertson, 1985: On the use and significance of isentropic potential vorticity maps. Quart. J. Roy. Meteor. Soc., 111, 877-946, https://doi.org/10.1002/ qj. 49711147002.

Hu, H., F. Dominguez, Z. Wang, D. A. Lavers, G. Zhang, and F. M. Ralph, 2017: Linking atmospheric river hydrological impacts on the U.S. West Coast to Rossby wave breaking. J. Climate, 30, 3381-3399, https://doi.org/10.1175/JCLI-D-16-0386.1.

Knox, J. A., J. D. Frye, J. D. Durkee, and C. M. Fuhrmann, 2011: Non-convective high winds associated with extratropical cyclones. Geogr. Compass, 5, 63-89, https://doi.org/10.1111/ j.1749-8198.2010.00395.x.

Kuo, Y. H., M. A. Shapiro, and E. G. Donall, 1991: The interaction between baroclinic and diabatic processes in a numerical simulation of a rapidly intensifying extratropical marine cyclone. Mon. Wea. Rev., 119, 368-384, https://doi.org/10.1175/ 1520-0493(1991)119<0368:TIBBAD>2.0.CO;2.

Lackmann, G. M., 2002: Cold-frontal potential vorticity maxima, the low-level jet, and moisture transport in extratropical cyclones. Mon. Wea. Rev., 130, 59-74, https://doi.org/10.1175/ 1520-0493(2002)130<0059:CFPVMT>2.0.CO;2.

Lavers, D. A., and G. Villarini, 2015: The contribution of atmospheric rivers to precipitation in Europe and the United States. J. Hydrol., 522, 382-390, https://doi.org/10.1016/ j.jhydrol.2014.12.010.

_ M. J. Rodwell, D. S. Richardson, F. M. Ralph, J. D. Doyle, C. A. Reynolds, V. Tallapragada, and F. Pappenberger, 2018: The gauging and modeling of rivers in the sky. Geophys. Res. Lett., 45, 7828-7834, https://doi.org/10.1029/2018GL079019.

—_, and Coauthors, 2020: Forecast errors and uncertainties in atmospheric rivers. Wea. Forecasting, 35, 1447-1458, https:// doi.org/10.1175/WAF-D-20-0049.1.

Madonna, E., H. Wernli, H. Joos, and O. Martius, 2014: Warm conveyor belts in the ERA-Interim dataset (1979-2010). Part I: Climatology and potential vorticity evolution. J. Climate, 27, 3-26, https://doi.org/10.1175/JCLI-D-12-00720.1.

Marciano, C. G., G. M. Lackmann, and W. A. Robinson, 2015: Changes in U.S. East Coast cyclone dynamics with climate change. J. Climate, 28, 468-484, https://doi.org/10.1175/JCLID-14-00418.1.
Martin, A. C., F. M. Ralph, A. Wilson, L. DeHaan, and B. Kawzenuk, 2019: Rapid cyclogenesis from a mesoscale frontal wave on an atmospheric river: Impacts on forecast skill and predictability during atmospheric river landfall. J. Hydrometeor., 20, 1779-1794, https://doi.org/10.1175/JHM-D-18-0239.1.

Neiman, P. J., F. M. Ralph, G. A. Wick, J. D. Lundquist, and M. D. Dettinger, 2008: Meteorological characteristics and overland precipitation impacts of atmospheric rivers affecting the West Coast of North America based on eight years of SSM/I satellite observations. J. Hydrometeor., 9, 22-47, https://doi.org/ 10.1175/2007JHM855.1.

_ L. J. Schick, F. M. Ralph, M. Hughes, and G. A. Wick, 2011: Flooding in western Washington: The connection to atmospheric rivers. J. Hydrometeor., 12, 1337-1358, https://doi.org/ 10.1175/2011JHM1358.1.

Newman, M., G. N. Kiladis, K. M. Weickmann, F. M. Ralph, and P. D. Sardeshmukh, 2012: Relative contributions of synoptic and low-frequency eddies to time-mean atmospheric moisture transport, including the role of atmospheric rivers. J. Climate, 25, 7341-7361, https://doi.org/10.1175/JCLI-D-11-00665.1.

Novak, D. R., B. A. Colle, and S. E. Yuter, 2008: High-resolution observations and model simulations of the life cycle of an intense mesoscale snowband over the northeastern United States. Mon. Wea. Rev., 136, 1433-1456, https://doi.org/ 10.1175/2007MWR2233.1.

Ralph, F. M., and M. D. Dettinger, 2012: Historical and national perspectives on extreme West Coast precipitation associated with atmospheric rivers during December 2010. Bull. Amer. Meteor. Soc., 93, 783-790, https://doi.org/10.1175/BAMS-D11-00188.1.

— , P. J. Neiman, and G. A. Wick, 2004: Satellite and CALJET aircraft observations of atmospheric rivers over the eastern North Pacific Ocean during the winter of 1997/98. Mon. Wea. Rev., 132, 1721-1745, https://doi.org/10.1175/1520-0493(2004) 132<1721:SACAOO $>2.0 . C O ; 2$.

- _ — , and R. Rotunno, 2005: Dropsonde observations in low-level jets over the northeastern Pacific Ocean from CALJET-1998 and PACJET-2001: Mean vertical-profile and atmospheric-river characteristics. Mon. Wea. Rev., 133, 889910, https://doi.org/10.1175/MWR2896.1.

,,-- G. A. Wick, S. I. Gutman, M. D. Dettinger, D. R. Cayan, and A. B. White, 2006: Flooding on California's Russian River: Role of atmospheric rivers. Geophys. Res. Lett., 33, L13801, https://doi.org/10.1029/2006GL026689.

,,-- G. N. Kiladis, K. Weickmann, and D. W. Reynolds, 2011: A multi-scale observational case study of a Pacific atmospheric river exhibiting tropical-extratropical connections and a mesoscale frontal wave. Mon. Wea. Rev., 139, 11691189, https://doi.org/10.1175/2010MWR3596.1.

—, T. Coleman, P. J. Neiman, R. J. Zamora, and M. D. Dettinger, 2013: Observed impacts of duration and seasonality of atmospheric-river landfalls on soil moisture and runoff in coastal northern California. J. Hydrometeor., 14, 443-459, https://doi.org/10.1175/JHM-D-12-076.1.

- J. M. Cordeira, P. J. Neiman, and M. Hughes, 2016: Landfalling atmospheric rivers, the Sierra barrier jet, and extreme daily precipitation in Northern California's Upper Sacramento River watershed. J. Hydrometeor., 17, 1905-1914, https://doi.org/10.1175/JHM-D-15-0167.1.

_ , and Coauthors, 2017: Dropsonde observations of total water vapor transport within North Pacific atmospheric rivers. J. Hydrometeor., 18, 2577-2596, https://doi.org/10.1175/JHMD-17-0036.1. 
, M. D. Dettinger, M. M. Cairns, T. J. Galarneau, and J. Eylander, 2018: Defining "atmospheric river": How the Glossary of Meteorology helped resolve a debate. Bull. Amer. Meteor. Soc., 99, 837-839, https://doi.org/10.1175/BAMS-D17-0157.1.

— - J. J. Rutz, J. M. Cordeira, M. Dettinger, M. Anderson, D. Reynolds, L. J. Schick, and C. Smallcomb, 2019: A scale to characterize the strength and impacts of atmospheric rivers. Bull. Amer. Meteor. Soc., 100, 269-289, https://doi.org/ 10.1175/BAMS-D-18-0023.1.

—, M. Dettinger, L. Schick, and M. Anderson, 2020a: Introduction to atmospheric rivers. Atmospheric Rivers, F. M. Ralph et al., Eds., Springer, 1-13.

—_ , and Coauthors, 2020b: West Coast forecast challenges and development of atmospheric river reconnaissance. Bull. Amer. Meteor. Soc., 101, E1357-E1377, https://doi.org/ 10.1175/BAMS-D-19-0183.1.

Reynolds, C. A., J. D. Doyle, F. M. Ralph, and R. Demirdjian, 2019: Adjoint sensitivity of North Pacific atmospheric river forecasts. Mon. Wea. Rev., 147, 1871-1897, https://doi.org/ 10.1175/MWR-D-18-0347.1.

Rutz, J. J., W. J. Steenburgh, and F. M. Ralph, 2014: Climatological characteristics of atmospheric rivers and their inland penetration over the western United States. Mon. Wea. Rev., 142, 905-921, https://doi.org/10.1175/MWR-D-13-00168.1.

Saha, S., and Coauthors, 2010: The NCEP climate forecast system reanalysis. Bull. Amer. Meteor. Soc., 91, 1015-1058, https:// doi.org/10.1175/2010BAMS3001.1.

Sanders, F., and J. R. Gyakum, 1980: Synoptic-dynamic climatology of the "bomb." Mon. Wea. Rev., 108, 1589-1606, https://doi.org/ 10.1175/1520-0493(1980)108<1589:SDCOT>2.0.CO;2.

Schultz, D. M., and Coauthors, 2019: Extratropical cyclones: A century of research on meteorology's centerpiece. A Century of Progress in Atmospheric and Related Sciences: Celebrating the American Meteorological Society Centennial, Meteor. Monogr., No. 59, Amer. Meteor. Soc., https://doi.org/10.1175/ AMSMONOGRAPHS-D-18-0015.1.

Sodemann, H., and A. Stohl, 2013: Moisture origin and meridional transport in atmospheric rivers and their association with multiple cyclones. Mon. Wea. Rev., 141, 2850-2868, https:// doi.org/10.1175/MWR-D-12-00256.1.

- and Coauthors, 2020: Structure, process, and mechanism. Atmospheric Rivers, F. M. Ralph et al., Eds., Springer, 15-43.
Stoelinga, M. T., 1996: A potential vorticity-based study of the role of diabatic heating and friction in a numerically simulated baroclinic cyclone. Mon. Wea. Rev., 124, 849-874, https://doi.org/ 10.1175/1520-0493(1996)124<0849:APVBSO > 2.0.CO;2.

Stohl, A., C. Forster, and H. Sodemann, 2008: Remote sources of water vapor forming precipitation on the Norwegian west coast at $60^{\circ} \mathrm{N}-\mathrm{A}$ tale of hurricanes and an atmospheric river. J. Geophys. Res., 113, D05102, https://doi.org/ 10.1029/2007JD009006.

Wernli, H., and H. C. Davies, 1997: A Lagrangian-based analysis of extratropical cyclones. I: The method and some applications. Quart. J. Roy. Meteor. Soc., 123, 467-489, https://doi.org/ 10.1002/qj.49712353811.

Whitaker, J. S., and C. A. Davis, 1994: Cyclogenesis in a saturated environment. J. Atmos. Sci., 51, 889-908, https://doi.org/ 10.1175/1520-0469(1994)051<0889:CIASE > 2.0.CO;2.

Willison, J., W. A. Robinson, and G. M. Lackmann, 2013: The importance of resolving mesoscale latent heating in the North Atlantic storm track. J. Atmos. Sci., 70, 2234-2250, https:// doi.org/10.1175/JAS-D-12-0226.1.

Zhang, Z., and B. A. Colle, 2017: Changes in extratropical cyclone precipitation and associated processes during the twenty-first century over eastern North America and the western Atlantic using a cyclone-relative approach. J. Climate, 30, 8633-8656, https://doi.org/10.1175/JCLI-D-16-0906.1.

—, and —, 2018: Impact of dynamically downscaling two CMIP5 models on the historical and future changes in winter extratropical cyclones along the East Coast of North America. J. Climate, 31, 8499-8525, https://doi.org/10.1175/JCLI-D-180178.1.

— , F. M. Ralph, and M. Zheng, 2019: The relationship between extratropical cyclone strength and atmospheric river intensity and position. Geophys. Res. Lett., 46, 1814-1823, https:// doi.org/10.1029/2018GL079071.

Zheng, M., and Coauthors, 2021: Data gaps within atmospheric rivers over the northeastern Pacific. Bull. Amer. Meteor. Soc., 102, 492-524, https://doi.org/10.1175/BAMS-D-19-0287.1.

Zhu, Y., and R. E. Newell, 1994: Atmospheric rivers and bombs. Geophys. Res. Lett., 21, 1999-2002, https://doi.org/10.1029/ 94GL01710.

— , and — 1998: A proposed algorithm for moisture fluxes from atmospheric rivers. Mon. Wea. Rev., 126, 725-735, https://doi.org/ 10.1175/1520-0493(1998)126<0725:APAFMF>2.0.CO;2. 